\title{
Simultaneous Ablation of Neuronal Neurofascin and Ankyrin G in Young and Adult Mice Reveals Age- Dependent Increase in Nodal Stability in Myelinated Axons and Differential Effects on the Lifespan
}

\author{
(1)Anna M. Taylor, Qian Shi, and ํㅣㄹanzoor A. Bhat
}

DOI:http://dx.doi.org/10.1523/ENEURO.0138-18.2018

Department of Cellular and Integrative Physiology, Center for Biomedical Neuroscience, University of Texas Health Science Center, San Antonio, Tx 78229

\section{Visual Abstract}

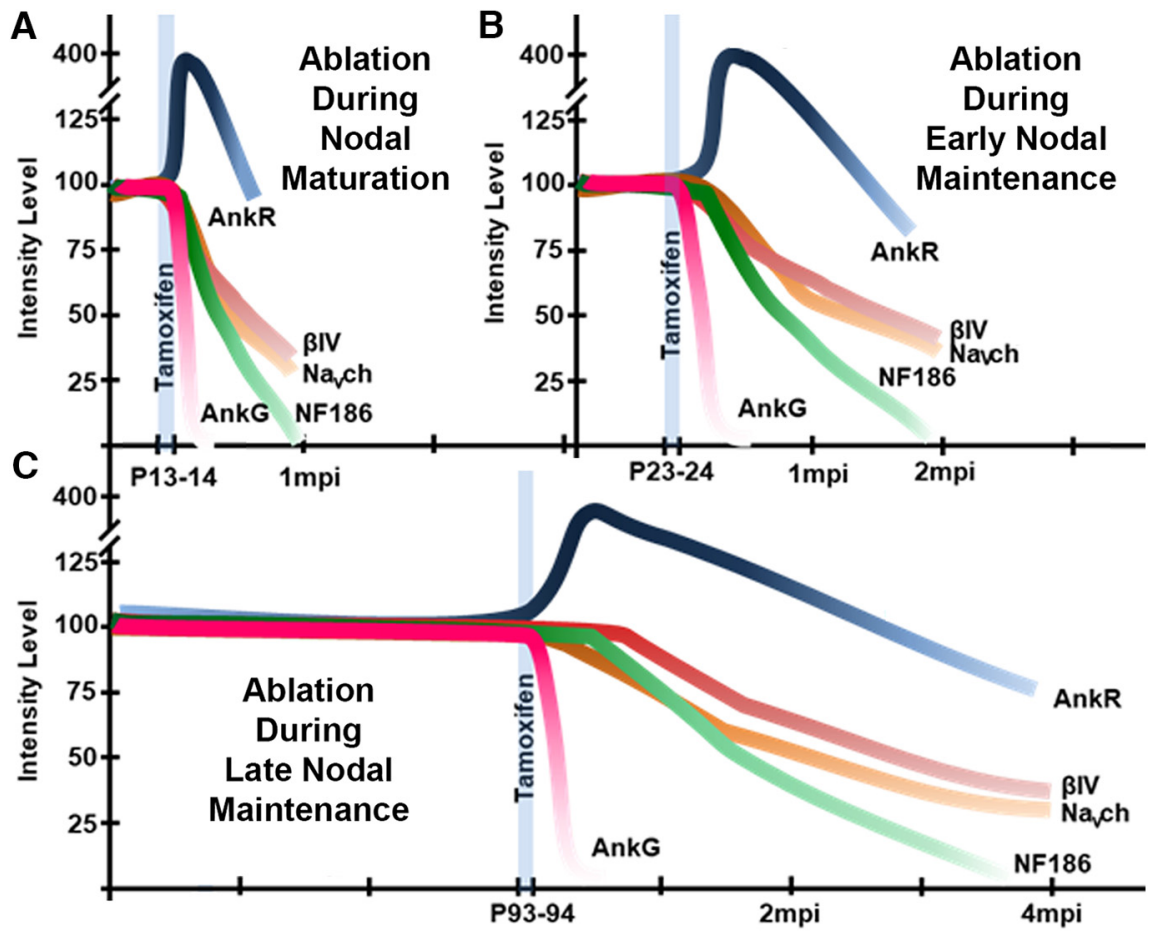

\section{Significance Statement}

The initial clustering, maturation, and lifelong maintenance of nodes of Ranvier along myelinated axons are vital to the saltatory propagation of action potentials, allowing for rapid movements. To investigate if the kinetics for nodal destabilization are variable with age, we used a novel mouse model in which two essential nodal proteins, Neurofascin 186 (NF186) and Ankyrin G (AnkG), were simultaneous ablated from neurons at different time points. Our studies show not only that nodal stability after maturation is dependent on the synergistic functions of these core nodal components, but also that nodes become more stable as animals age, which is relevant to human demyelination disorders. 
Nodes of Ranvier are unique regions where voltage-gated sodium channels are highly enriched to drive saltatory conduction. Genetic ablations in adult mice with loss of specific nodal proteins causes slow but progressive nodal deterioration associated with decreased nerve conduction and axonopathy. What has remained unaddressed is whether loss of nodal proteins at different time points in postnatal life follows similar timelines of nodal disorganization. Here we utilized simultaneous ablation of Neurofascin (NF186) and Ankyrin G (AnkG) in mice of both sexes at three specific time points. We report that concurrent ablation of these core nodal components at postnatal day 13 (P13) leads to accelerated nodal destabilization in comparison with P23, and this disorganization is even slower when ablated at P93. Ablation of NF186 with AnkG at P13 reduced the half-life of NF186 to 15 days compared to 1 month at P23, which increased to 2 months at P93, indicating increasing nodal stability. The half-life of AnkG at the nodes also increased with age but showed enhanced disappearance from the node in the absence of NF186, with a half-life of 3 days at P13 ablation. The nodal disorganization occurred in a sequential manner, with AnkG disappearing first from the nodal areas irrespective of the timing of ablation, and led to decreased nerve conduction and affected axonal health. Together, our studies reveal that nodes of Ranvier in myelinated axons continue to become more stable with age and suggest that nodal disorganization in adult human demyelinating disorders occurs slowly until neurological symptoms become evident.

Key words: Ankyrin G; Axon degeneration; maintenance of nodes; myelination; nodes of Ranvier

\section{Introduction}

Intricate molecular complexes evolved to cluster ion channels into distinct domains along axons, including nodes of Ranvier (nodes), to allow for rapid movements in higher-order mammals. The nodal complex, which is critical to the saltatory propagation of action potentials, requires cell adhesion molecules as well as cytoskeletal scaffolding components to anchor ion channels. The core components of nodes have been well defined to include the 186-kDa neuron-specific isoform of Neurofascin (Nfasc $^{N F 186}$ ), NrCAM, Ankyrin-G (AnkG), $\beta$ IV Spectrin, and voltage-gated sodium $\left(\mathrm{Na}_{\mathrm{v}}\right.$ ) channels (Kordeli et al., 1995; Davis et al., 1996; Lambert et al., 1997; Komada and Soriano, 2002). However, the precise order in which these nodal components arrive and their individual roles in the establishment, maturation, and maintenance of nodes remain heavily debated (Buttermore et al., 2013; Nelson and Jenkins, 2017).

Recent focus, which has been fueled by the use of spatio-temporal ablation as well as double knockout of nodal components, has been to elucidate how the node is maintained throughout the lifespan and how this ulti-

Received April 7, 2018; accepted June 7, 2018; First published June 13, 2018. The authors declare no competing financial interests.

Author contributions: A.M.T. and M.A.B. designed research; A.M.T. and Q.S. performed research; A.M.T., Q.S., and M.A.B. analyzed data; A.M.T. and M.A.B. wrote the paper.

Grant support was provided by NIH NIGMS GM063074, National Multiple Sclerosis Society, the Zachry Foundation, the Owens Foundation, and the Morrison Trust (MAB). A.M.T. was supported by the NIH NINDS Postdoctoral Fellowship F32NS092448. Q.S. was supported by the JDRF 3-APF-2016-205-A-N.

Acknowledgments: We sincerely thank members of the Bhat lab for their valuable discussions and technical assistance. Electron microscopy was performed at the UT Health San Antonio electron microscopy facility.

Correspondence should be addressed to: Manzoor A. Bhat, Department of Cellular and Integrative Physiology, Center for Biomedical Neuroscience, University of Texas Health Science Center, San Antonio, TX, 78229. E-mail: bhatm@uthscsa.edu.

DOI:http://dx.doi.org/10.1523/ENEURO.0138-18.2018

Copyright (C) 2018 Taylor et al.

This is an open-access article distributed under the terms of the Creative Commons Attribution 4.0 International license, which permits unrestricted use, distribution and reproduction in any medium provided that the original work is properly attributed. mately relates to the health of myelinated axons (Pillai et al., 2009; Zonta et al., 2011; Zhang et al., 2012; Amor et al., 2014; Desmazieres et al., 2014; Saifetiarova et al., 2017; Taylor et al., 2017). Specifically through the use of an inducible, neuronal-specific driver to ablate either AnkG or NF186 from mature nodes, we previously reported that while these two key proteins are both necessary for the long-term maintenance of the node, they have inherently different stabilities, leading to differential kinetics of nodal disorganization and axonal pathology (Saifetiarova et al., 2017; Taylor et al., 2017). In both cases, disrupting the nodal complex after it was fully formed took more than half a year; however, ablating AnkG using this same model at an early time point before nodal formation resulted in nodes that clustered but then began to deteriorate (Saifetiarova et al., 2017). Instead of a pioneering role in the initial formation of the node, as was previously proposed (Jenkins and Bennett, 2002; Dzhashiashvili et al., 2007; Jenkins et al., 2015), these studies reveal an essential functional for AnkG in the stabilization of the node into a mature complex. Furthermore, these studies suggested that cytoskeletal and cell adhesion components play unique roles in nodal stability during specific stages of postnatal life.

In the current study, we addressed the combined roles of a cytoskeletal scaffolding component and a transmembrane cell adhesion protein in nodal stabilization, as well as the impact of age on nodal stability, by taking advantage of spatio-temporal ablation of both AnkG and NF186 at multiple time points from early maturation to long-term maintenance. We show that simultaneous ablation of AnkG along with NF186 from a fully formed node further reduces the stability of NF186, leading to enhanced kinetics of nodal destabilization, nerve conduction loss, and axonopathy compared to the single-ablation models. Inducing ablation of AnkG in combination with NF186 at an earlier time point led to even more rapid decline of NF186 stability and consequently the levels of $\mathrm{Na}_{\mathrm{v}}$ channels at the node. Although delaying ablation to later stages slowed nodal deterioration, loss of AnkG and NF186 ultimately had similar detrimental consequences on axonal 
health. Together, our studies suggest that nodal maturation occurs over time such that nodal complexes in older mice destabilize much more slowly than in younger mice, and that this age-dependent maturation increases the half-life of nodal proteins to ensure an optimal rate of nerve conduction by myelinated axons.

\section{Materials and Methods}

\section{Materials}

All chemical and reagents were purchased from SigmaAldrich, unless otherwise specified. Antisera used, which were previously described, include rabbit anti-AnkG, anti$\beta I V$ Spectrin, and anti-pan $\mathrm{Na}_{\mathrm{V}}$ Channels (Taylor et al., 2017), guinea pig and rabbit anti-Caspr (Bhat et al., 2001), guinea pig anti-NF186 (Thaxton et al., 2011), and rat anti-NFCT (Pillai et al., 2009). Primary antibodies include rabbit anti-Gapdh (RRID:AB_796208, \#G9545); mouse anti- $\beta$-actin (RRID:AB_476744, \#A-5441); mouse antiCaspr (RRID:AB_2083496, \#75-001, NeuroMab); antiAnkR (RRID:AB_2491109, \#75-380, NeuroMab); and anti-Kv1.2 (RRID:AB 2296313, \#75-008, NeuroMab). Fluorescent secondary antibodies (Alexa Fluor; Life Technologies) and infrared (IR)-conjugated secondary antibodies (LI-COR) were also purchased. Reagents used to perform electron microscopy were from Electron Microscopy Sciences.

\section{Animals and treatments}

To characterize the combined role of AnkG and Neurofascin in nodal maturation and maintenance, Ankyrin3 $3^{\text {Flox }}$ $\left(A n k^{f x}\right)$ mice (RRID:MGI:5538267), which were provided by Vann Bennett (Duke University; Paez-Gonzalez et al., 2011), and $N$ fasc ${ }^{F l o x}\left(N F^{f x}\right)$ mice (Pillai et al., 2009) were bred to generate a double $N F^{f x} ; A n k^{f x}$ mouse line. This double floxed line was then crossed with the singleneuron labeling with inducible Cre-mediated knockout (SLICK)-H (derivative of Thy1.2-CreER) transgenic mouse line (RRID:IMSR_JAX:012708), which were provided by Paul Young (Heimer-McGinn and Young, 2011), to specifically knock out AnkG and NF186 in neurons at various time points. Then, SLICK-H;NF ${ }^{+/ f x} ; A n k^{+/ f x}$ were bred to $N F^{+/ f x} ; A n k^{+/ f x}$ to generate controls $\left(N F^{f x / f x} ; A n k^{f x / f x} ;\right)$, single AnkG conditional knockouts (cKOs; SLICK-H;NF ${ }^{+/+}$; $A n k^{f x / f x}$ ), single NF186 cKOs (SLICK-H;NF $F^{f x / f x} ; A n k^{+/ x}$ ), and double AnkG/NF186 cKOs (SLICK-H;NF $F^{f x / f x} ; A n k^{f x / f x}$ ). These mice were maintained on a mixed-strain background of C57BL/6 and 129/Vs. Mice were genotyped before postnatal day 12 (P12) and weaned by P21. The mice were group-housed in a temperature-controlled animal facility $\left(23 \pm 1^{\circ} \mathrm{C}\right)$ with a maintained light cycle $(12 \mathrm{~h}$ light on/12 $\mathrm{h}$ off) and ad libitum access to water and a standard rodent diet.

To induce genetic ablation of AnkG, NF186, or both, tamoxifen (MP Biomedicals) suspended in sunflower seed oil $(1 \mathrm{mg} / \mu \mathrm{L})$ was delivered as intraperitoneal (i.p.) injections for 2, 5, or 10 consecutive days. As no increase in recombination was seen with additional doses, all studies presented in this manuscript used 2 consecutive doses of tamoxifen, either from $\mathrm{P} 13 / 14, \mathrm{P} 23 / 24$, or P93/94. To determine the dose of tamoxifen given, each mouse was weighed at the time of injection and injected with $1 \mathrm{mg} /$ $12.5 \mathrm{~g}$ body weight, which was the average weight calculated for P23/24 NF $F^{f x} ; A n k^{f x}$ mice and thus the dose used for previous published single AnkG and NF186 studies when $1 \mathrm{mg}$ was given daily between P23 and P32 (Saifetiarova et al., 2017; Taylor et al., 2017). At various time points postinjection, age-matched control, single AnkG cKO, and double AnkG/NF186 cKO littermates were evaluated by electrophysiological, immunohistochemical, biochemical, and ultrastructural techniques.

To promote survival after tamoxifen ablation of NF186 and AnkG, all mice regardless of genotype were provided with moist food on the floor of their cage after weaning. End stage was defined as the time at which mice placed on their backs could no longer right themselves. At this terminal stage, mice were humanely euthanized. All animal research was performed with prior approval from the Institutional Animal Care and Use Committee of the University of Texas Health Science Center at San Antonio in accordance with the Public Health Service Policy on Humane Care and Use of Laboratory Animals.

\section{Experimental design and statistical analysis}

For each experiment described, the number of mice used was designed based on the minimal number of animals necessary to determine high statistical differences $(P<0.01)$ between genotypes in previously reported studies. As no gender differences have been revealed at nodes of Ranvier, we used equal numbers of males and females per group (each genotype at all three different ablation timelines). For survival studies, 8-10 mice were used per group, and 6-8 mice per group at each time point postinjection studied were used for nerve conduction velocity (NCV) recordings. For immunostaining, tissues were processed from 3-4 mice per group per time point, then 50-70 nodes from PNS and 80-100 nodes from CNS were quantified per animal. For immunoblotting, tissues were processed and quantified from 3 mice per group at the terminal time point. For ultrastructure analyses, tissues were processed from 3 mice per group, and for each mouse a minimum of 200 axons for $\mathrm{SN}$ and 500 axons for SC were imaged.

All data are presented as the mean \pm SEM, where the $n$ always equals the number of mice/group. Relative values were arithmetically adjusted to yield a unit of 1 for the control group at each time point. To compare multiple time points across genotypes, two-way ANOVAs were performed followed by Tukey's multiple comparison analyses. When only a single time point was used, statistically significant differences between genotypes were determined using unpaired, two-tailed Student's $t$ tests. Statistical differences are represented in figures by $*(\mathrm{P}<$ $0.05)$, ** $(\mathrm{P}<0.01)$, *** $(\mathrm{P}<0.001)$ with black asterisks indicating differences between age-matched control and mutants; colored asterisks signify differences among the mutant groups at different ages (green for P13/14 induced, blue for P23/24 induced double, and red for P93/94 induced double AnkG/NF186 cKO). Significant differences in survival curves were determined by MantelCox log-rank test, which were evaluated individually and 
then corrected for multiple comparisons with the Bonferroni method. All statistical tests were performed using GraphPad Prism6 software (RRID:SCR_002798) and are summarized with exact $p$-values in Table 1.

\section{In vivo recordings}

At various time points post-tamoxifen, in vivo nerve conduction velocities (NCVs) and amplitudes were recorded from the sciatic nerve of aged matched control and double AnkG/NF186 cKO littermates. The mice were anesthetized by continuous isoflurane ( $5 \%$ aerosolized), and electrophysiological recordings were collected using a Nicolet Teca Synergy portable neurologic system (Natus Neurology) as previously described (Taylor et al., 2017). Briefly, the recording electrodes were placed in the dorsum of the foot, and two separate recordings were made: at the ankle $(0.02 \mathrm{~ms}, 4 \mathrm{~mA})$ and the sciatic notch $(0.02$ $\mathrm{ms}, 8 \mathrm{~mA}$ ). NCV studies were limited to the left sciatic nerve so that the right sciatic nerve could be used for further analyses.

\section{Immunofluorescence}

At various time points post-tamoxifen, control, single AnkG cKO, single NF186 cKO, and double AnkG/NF186 cKO littermates were anesthetized through an i.p. injection of Avertin (2\% 2-2-2 tribromoethanol in 2-methyl-2butanol). The right sciatic nerve was removed and fixed for $30 \mathrm{~min}$ in $4 \%$ paraformaldehyde (PFA) in $0.01 \mathrm{~m}$ PBS. Then the mouse was perfused intracardially using a peristaltic pump for 3 min with saline followed by 2 min with a chilled $1 \%$ PFA, $1 \%$ sucrose solution in $0.1 \mathrm{M}$ phosphate buffer (PB). Spinal cords were harvested, postfixed for $2 \mathrm{~h}$ at $4^{\circ} \mathrm{C}$ in the $1 \%$ PFA solution, and then allowed to submerge in $30 \%$ sucrose before being cryosectioned into 14- $\mu \mathrm{m}$ sections. After PBS washes, the sciatic nerve was teased on the slides and allowed to dry overnight. Immunostaining of both spinal cord slices and teased sciatic nerves was performed as previously described (Taylor et al., 2017).

\section{Image analysis}

Confocal images were acquired with a Zeiss LSM 710 Microscope using a $40 \times$ oil objective as previously described (Taylor et al., 2017). Briefly, identical settings were used to capture images from control and mutant samples, and images shown are maximal-intensity projections from Z-stacks with $0.4-\mu \mathrm{m}$ interval. For quantification of nodal intensities, three z-stack images were taken for each mouse, and a minimum of 50 nodes for each nodal marker per tissue were quantified. All values were arithmetically adjusted to yield a unit of 1 for the control group at each time point.

\section{Immunoblotting}

Sciatic nerve and spinal cord were collected from anesthetized control, single AnkG cKO, and double AnkG/ NF186 cKO littermates at various time points posttamoxifen and stored at $-80^{\circ} \mathrm{C}$ until processing. Tissues were homogenized in ice-cold RIPA buffer $(25 \mathrm{~mm}$ Tris$\mathrm{HCl}, \mathrm{pH} 7.5,150 \mathrm{~mm} \mathrm{NaCl}, 1 \mathrm{~mm}$ EDTA, 1\% NP-40, and $5 \%$ glycerol) with protease inhibitors (\#A32953, Thermo
Fisher Scientific) and phosphatase inhibitor mix (RRID: AB_10189608, \#sc-45044, Santa Cruz Biotechnology). The lysates were sonicated for $10 \mathrm{~s}$ before centrifugation at $13,000 \times g$ at $4^{\circ} \mathrm{C}$ for $30 \mathrm{~min}$. The supernatant was then mixed with $6 \times$ sample buffer and heated to $37^{\circ} \mathrm{C}$, and immunoblotting was conducted as previously described (Saifetiarova et al., 2017). When using IR-conjugated secondary antibodies (1:10000 for $1 \mathrm{~h}$ ), membranes were imaged using an Odyssey scanner (LI-COR).

The intensities of Western blot bands were quantified using ImageJ software (RRID:SCR_003070; NIH) and normalized to $\beta$-actin or GAPDH loading controls. Specifically, for AnkG immunoblots, the 270- and 480-kDa band intensities from each animal were added together and are reported as a single relative protein level. The normalized intensity of each protein within each group was calculated by averaging band intensity from three mice, and representative blots for each protein are shown.

\section{Electron microscopy}

Double AnkG/NF186 cKO and controls at the specified time points post-tamoxifen were anesthetized and perfused intracardially using a peristaltic pump with saline for 10 min followed by a $5 \%$ glutaraldehyde: $4 \%$ PFA solution prepared in sodium cacodylate buffer for $30 \mathrm{~min}$. After perfusion, the whole animal was submerged in the $5 \% / 4 \%$ fixative for at least 1 week before the spinal cord and sciatic nerve were dissected. The tissues were cut into 1-mm square pieces and processed as described (Green et al., 2013; Taylor et al., 2017). Once embedded in Polybed, the blocks were submitted to the UTHSCSA Electron Microscopy Lab for sectioning and contraststaining. Grids were imaged on a JEOL 1230 transmission electron microscope using an Advanced Microscopy Techniques camera and software (Woburn, MA).

\section{Results}

\section{Simultaneous loss of neurofascin 186 with ankyrin G dramatically reduces lifespan}

A unique molecular interplay between cell adhesion and cytoskeletal scaffolding proteins drives the clustering of ion channels at nodes of Ranvier along myelinated axons. While the cytoskeletal component, AnkG, binds to $\beta \mathrm{IV}$ Spectrin, $\mathrm{Na}_{V}$ channels, and NF186 intracellularly, the transmembrane NF186 extends beyond the cell membrane, interacting with glial extracellular matrix proteins (depicted in Fig. 1A). Although the individual roles of these proteins in the initial formation of the node have been well studied, their roles in nodal stability have only recently begun to be elucidated (Saifetiarova et al., 2017; Taylor et al., 2017). The combined contributions of AnkG and NF186 in nodal maintenance and what impact their combined loss would have on the nodal domain as well as the animal lifespan has not been addresesd.

To study the combined contributions of AnkG [encoded by Ankyrin 3 (Ank3)] and neuronal $\mathrm{Nfasc}^{\mathrm{NF} 186}$ to the stability of the nodal complex at different developmental stages that coincide with myelination and axonal domain organization (Fig. 1B), we crossed Ank3 $3^{\text {Flox }}\left(A n k^{f x}\right)$ mice (Paez-Gonzalez et al., 2011) with Nfasc ${ }^{\text {Flox }}\left(N F^{f x}\right)$ mice 
A

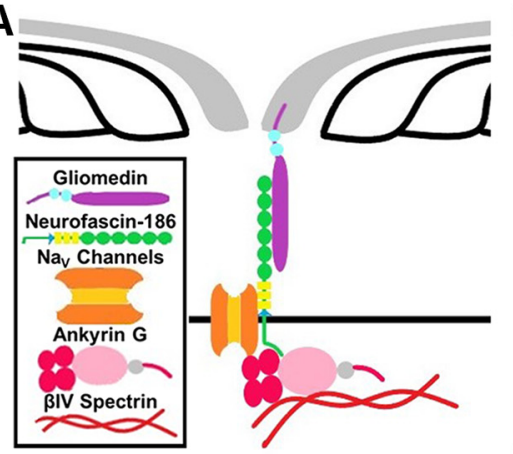

B

Nodal Maintenance

\section{Nodal Maturation}

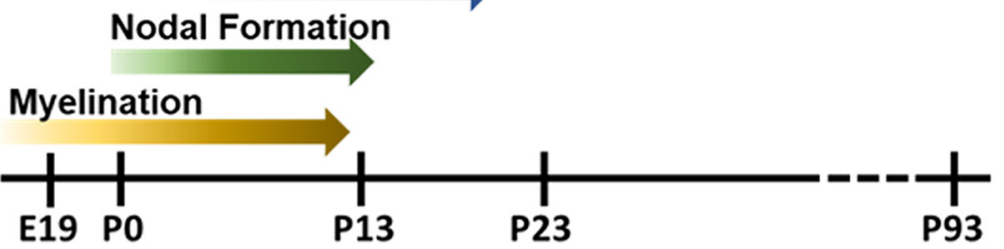

Experimental Design
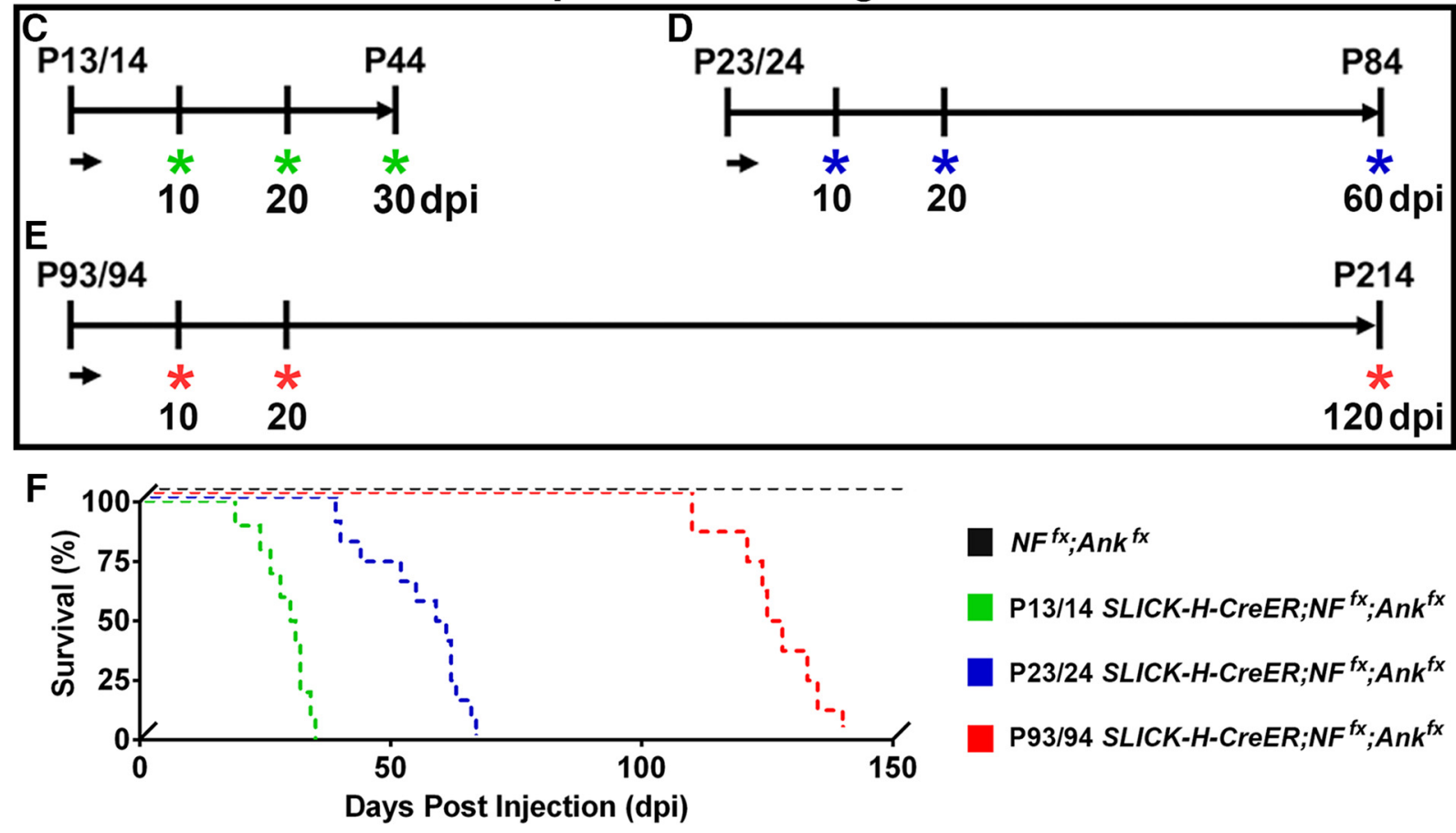

$N F^{f x} ; A n k^{f x}$

$\mathrm{P} 13 / 14$ SLICK-H-CreER;NF ${ }^{f x} ; A_{n k}{ }^{f x}$

P23/24 SLICK-H-CreER;NF ${ }^{f x} ; A n k^{f x}$

P93/94 SLICK-H-CreER;NF ${ }^{f x} ; A n k^{f x}$

G

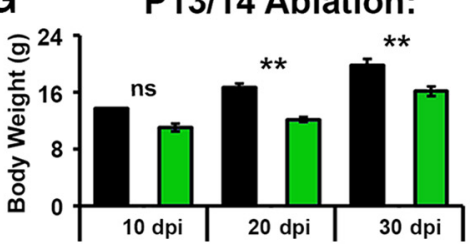

H

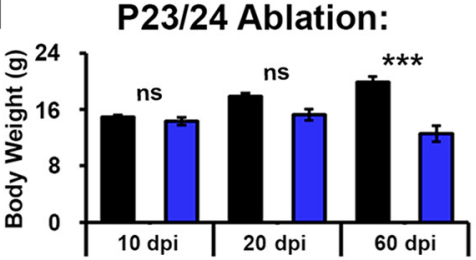

I

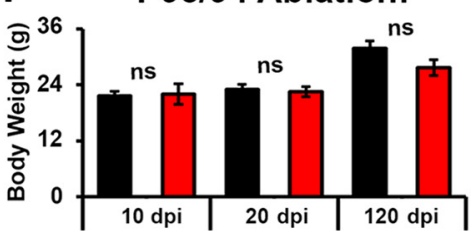

Figure 1. Timing of NF186/AnkG ablation alters survival. $\boldsymbol{A}$, Schematic diagram of key proteins involved in the organization and/or stabilization of nodes of Ranvier within myelinated fibers in the PNS. B, Timeline of myelination, nodal formation, maturation, and nodal maintenance in mice. $\boldsymbol{C}-\boldsymbol{E}$, Schematic representation of tamoxifen injections schemes for Ank3 and Nfasc ${ }^{N F 186}$ ablation from myelinated axons. SLICK-H-CreER;NF $F^{f x} ; A n k^{f x}$ and $N F^{f x} ; A n k^{f x}$ control mice were injected at P13/14 (C), P23/24 (D), or P93/94 (E) and analyzed 10, 20, 30, 60, or $120 \mathrm{dpi}$. (F) Survival curve representing the numbers of days lived after tamoxifen ablation for SLICK-H-CreER;NF ${ }^{f x} ; A n k^{f x}$ mice injected at P13/14 (green line), P23/24 (blue line), or P93/94 (red line) compared to age-matched $N F^{f x}$;Ank $k^{f x}$ littermates (black line). Each curve is significantly different $(p<0.0001)$ from each other by Mantel-Cox log rank test, Bonferroni post hoc analysis ( $n=8-10$ mice/group). G-I, Graph representing the body weight of $N F^{f x}$; Ank ${ }^{f x}$ (black bar) and SLICK-H-CreER;NF ${ }^{f x}$;Ank ${ }^{f x}$ mice injected at P13/14 (G, green bar), P23/24 (H, blue bar), or P93/94 (I, red bar). Black asterisks indicate statistical differences between control and mutant at each time point by two-way ANOVA, Tukey post hoc analysis $(n=8-10$ mice/group). Data are represented as mean \pm SEM.

(Pillai et al., 2009) to generate double $N F^{f x} ; A n k^{f x}$. This double floxed line was crossed with SLICK-H mice, which use a Thy1.2 promoter modified to be specifically expressed in neurons (Caroni, 1997; Young et al., 2008). Thus, genotypes of control $\left(N F^{f x} ; A n k^{f x}\right)$, single AnkG cKO
$\left(S L I C K-H ; A n k^{f x}\right)$, single NF186 cKO (SLICK-H;NF ${ }^{f x}$ ), and double AnkG/NF186 cKO (SLICK-H;NF $\left.{ }^{f x} ; A n k^{f x}\right)$ were generated.

Controls, single, and double AnkG/NF186 cKO littermates were given tamoxifen injections for 2 consecutive 
days starting at $\mathrm{P} 13$ to specifically ablate AnkG and/or NF186 from neurons after the initial clustering of nodes of Ranvier had begun during the stage of nodal maturation (Fig. 1C). These mice were examined at 10, 20, and 30 days post injection (dpi), as $\mathrm{P} 13 / 14$ ablated SLICK-H;NF' $A n k^{f x}$ rarely survived past 35 dpi (Fig. $1 F$ ). As early as 5 dpi, double AnkG/NF186 cKO were distinguishable from their littermates by altered gait and tremor. By $20 \mathrm{dpi}$, these phenotypes progressed to include significantly reduced body weight in the double AnkG/NF186 cKO at $12.2 \pm 0.4 \mathrm{~g}$ compared to matched controls at $16.7 \pm 0.5$ g (Fig. 1G). By 30 dpi, surviving double AnkG/NF186 cKO mice displayed hindlimb clasping, kyphosis, and paresis, which was never observed in tamoxifen-injected controls and did not begin to appear in $\mathrm{P} 13 / 14$ single-ablated AnkG or NF186 cKO until after $30 \mathrm{dpi}$.

To further examine the combined roles of AnkG and NF186 in the maintenance of nodes after nodal clustering is complete, controls, single, and double AnkG/NF186 cKOs littermates were injected with tamoxifen for 2 consecutive days starting at P23 during adolescence (Fig. 1D). These mice were examined at 10,20 , and $60 \mathrm{dpi}$, as SLICK-H;NF ${ }^{f x} ; A n k^{f x}$ injected at P23/24 did not survive beyond an average of $60 \mathrm{dpi}$ (Fig. 1F). This median survival age was significantly longer than those ablated at $\mathrm{P} 13 / 14$, which showed a median survival age of 30.5 dpi $\left(\chi^{2}=25.28 ; p<0.0001\right.$, Mantel-Cox). By $10 \mathrm{dpi}$, double AnkG/NF186 cKOs ablated at P23/24 displayed a defined tremor, which developed into an altered gait and hindlimb clasping by $20 \mathrm{dpi}$. Although the phenotype was delayed compared to the $\mathrm{P} 13 / 14$ injected double cKOs, those double cKOs injected at P23 ultimately showed partial hindlimb paralysis and severe spinal deformation by $60 \mathrm{dpi}$, which as previously reported was not seen until 6 months postinjection (mpi) in SLICK-H;NF ${ }^{f x /-}$ and $8 \mathrm{mpi}$ in SLICK-H;Ank ${ }^{f \times /-}$ (Saifetiarova et al., 2017; Taylor et al., 2017). In addition to ataxic phenotype and shortened lifespan, a significant reduction in body weight was observed at $60 \mathrm{dpi}$ in P23/24 ablated double cKOs $(12.6 \pm 1.1 \mathrm{~g})$ compared to matched controls $(19.9 \pm 0.8 \mathrm{~g}$; Fig. $1 H)$. Together these initial results reveal that despite the timing of ablation, combined loss of the cell adhesion molecule NF186 with the cytoskeletal component AnkG leads to an enhanced phenotype and ultimately quicker demise of the animals compared to single ablation of NF186 or AnkG, which suggest a synergistic function of these proteins. Furthermore, delaying the stage at which ablation of AnkG and NF186 occurred by just 10 days led to essentially a doubling of the survival postinjection.

To thoroughly examine nodal stability at different stages, we next asked if delaying ablation of AnkG and NF186 to a time point later in adult life would lead to any further change in the kinetics of nodal destabilization, as one might hypothesize that once a node has fully matured, no changes would be seen in the timeline. Controls and double AnkG/NF186 cKO littermates were injected with tamoxifen for 2 consecutive days starting at P93/94 (Fig. 1E). These mice were examined at 10, 20, and 120 dpi, as SLICK-H;NF ${ }^{f x} ; A n k^{f x}$ ablated at P93 had a median survival rate of $126.5 \mathrm{dpi}$, which was significantly longer than those injected at $\mathrm{P} 13 / 14$ and $\mathrm{P} 23 / 24$ (Fig. $1 F ; \chi^{2}=$ 17.72 and 18.68, respectively; $p<0.0001$, Mantel-Cox). The double AnkG/NF186 cKOs were indistinguishable compared to control littermates at $30 \mathrm{dpi}$ and did not begin to display tremor or altered gait until $60 \mathrm{dpi}$. By endpoint, the P93 ablated double cKOs showed significant kyphosis, hindlimb clasping, and paresis. Although the double AnkG/NF186 cKOs ablated at P93/94 ultimately displayed ataxia, these mice did not show any significant reduction in body weight compared to littermate controls, unlike the double cKOs ablated at P13/14 and P23/24 (Fig. 1/). Together, these data indicate that loss of AnkG/NF186 at $\sim 3$ months of adult life has a less dramatic impact on survival than at early stages and further suggest nodal disorganization may occur at different rates depending on the age of the node.

\section{Neurofascin 186 and AnkG show differential stability during nodal maturation and maintenance}

To confirm the ablation of AnkG and NF186 in the single and double AnkG/NF186 cKOs compared to controls, as well as to determine any difference in stability due to the timing of ablation, sciatic nerves (SNs) and spinal cords (SCs) at various time points were triple immunostained with antibodies against AnkG (red), NF186 (blue), and pan-Neurofascin (NFCT, which detects paranodal NF155 and nodal NF186) or Caspr, respectively (green, Fig. 2). As is seen in the $N F^{f x}$; $A n k^{f x}$ column at all ages, control mice have a tight clustering of AnkG colocalized with NF186 at the node surrounded by the flanking paranodes in the PNS (Fig. 2A-l), which is sometimes flanked with a less intense paranodal AnkG staining in the CNS (Fig. $2 A^{\prime}-l^{\prime}$ ), due to the oligodendrocyte expression of AnkG, as was previously reported (Chang et al., 2014).

After ablation at $\mathrm{P} 13 / 14$ during nodal maturation, single SLICK-H;Ank ${ }^{f x}$ showed a significant increase in the number of nodes, with no detectable levels of AnkG in SN over time from $14.4 \pm 2.6 \%$ at $10 \mathrm{dpi}$ to $88.2 \pm 2.9 \%$ at $30 \mathrm{dpi}$; however, there was no change in the number of nodes with NF186, which remained at control levels (Fig. $2 A-C$, J). In contrast, after P13 ablation, double SLICK-H;NF ${ }^{f x ;}$ $A n k^{f x}$ had no change in the number of nodes lacking AnkG, which was already $89.4 \pm 3.8 \%$ at $10 \mathrm{dpi}$, and instead showed a significant increase in nodes with no detectable levels of NF186 from $1.8 \pm 1.3 \%$ at $10 \mathrm{dpi}$ to $65.0 \pm 4.4 \%$ at $30 \mathrm{dpi}$ (Fig. 2J). Although the number of nodes without detectable NF186 $(65.0 \pm 4.4 \%)$ had not dropped to the same percentage as nodes found without AnkG $(90.4 \pm 0.8 \%)$ by $30 \mathrm{dpi}$ in the double AnkG/NF186 cKO, a significantly reduced intensity level of NF186 $(12.0 \%)$ was measured at the nodes compared to agematched controls (Fig. 2M). As in the PNS, P13/14 ablated single SLICK-H;Ank ${ }^{f x}$ showed increasing amounts of AnkG-negative nodes in the SC from $48.7 \pm 0.7 \%$ at 10 dpi to $82.4 \pm 2.5 \%$ at $30 \mathrm{dpi}$, but no significant change in the number of nodes without NF186 (Fig. $2 A^{\prime}-C^{\prime}, J^{\prime}$ ). Although in the SC the number of nodes without AnkG in double cKOs was $>90 \%$ by $10 \mathrm{dpi}$ and remained steady, 


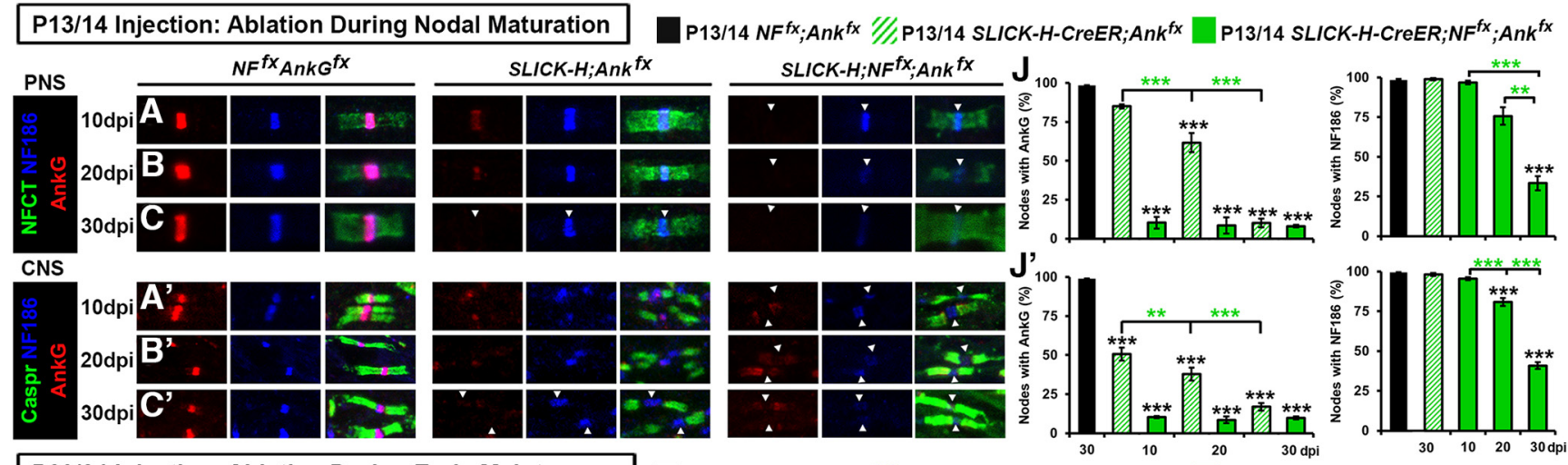

P23/24 Injection: Ablation During Early Maintenance 口P23/24 NF ${ }^{f x} ; A n k^{f x}$ W//P23/24 SLICK-H-CreER;Ank ${ }^{f x}$ P23/24 SLICK-H-CreER;NFfx;Ank ${ }^{f x}$
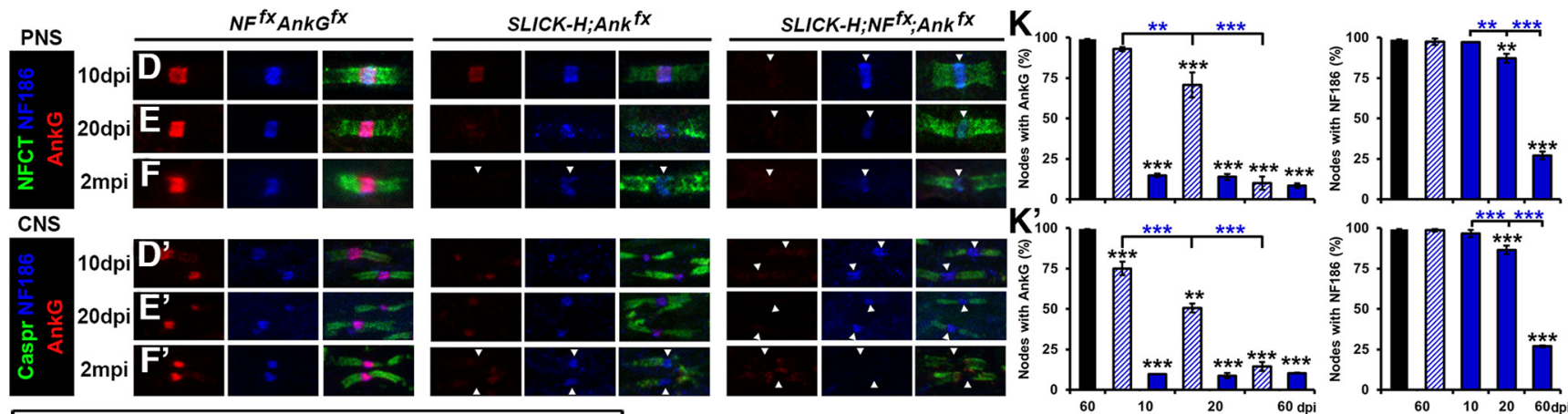

P93/94 Injection: Ablation During Late Maintenance $\quad$ P93/94 NFfx;Ank ${ }^{f x}$ P93/94 SLICK-H-CreER;NF ${ }^{f x} ; A n k^{f x}$
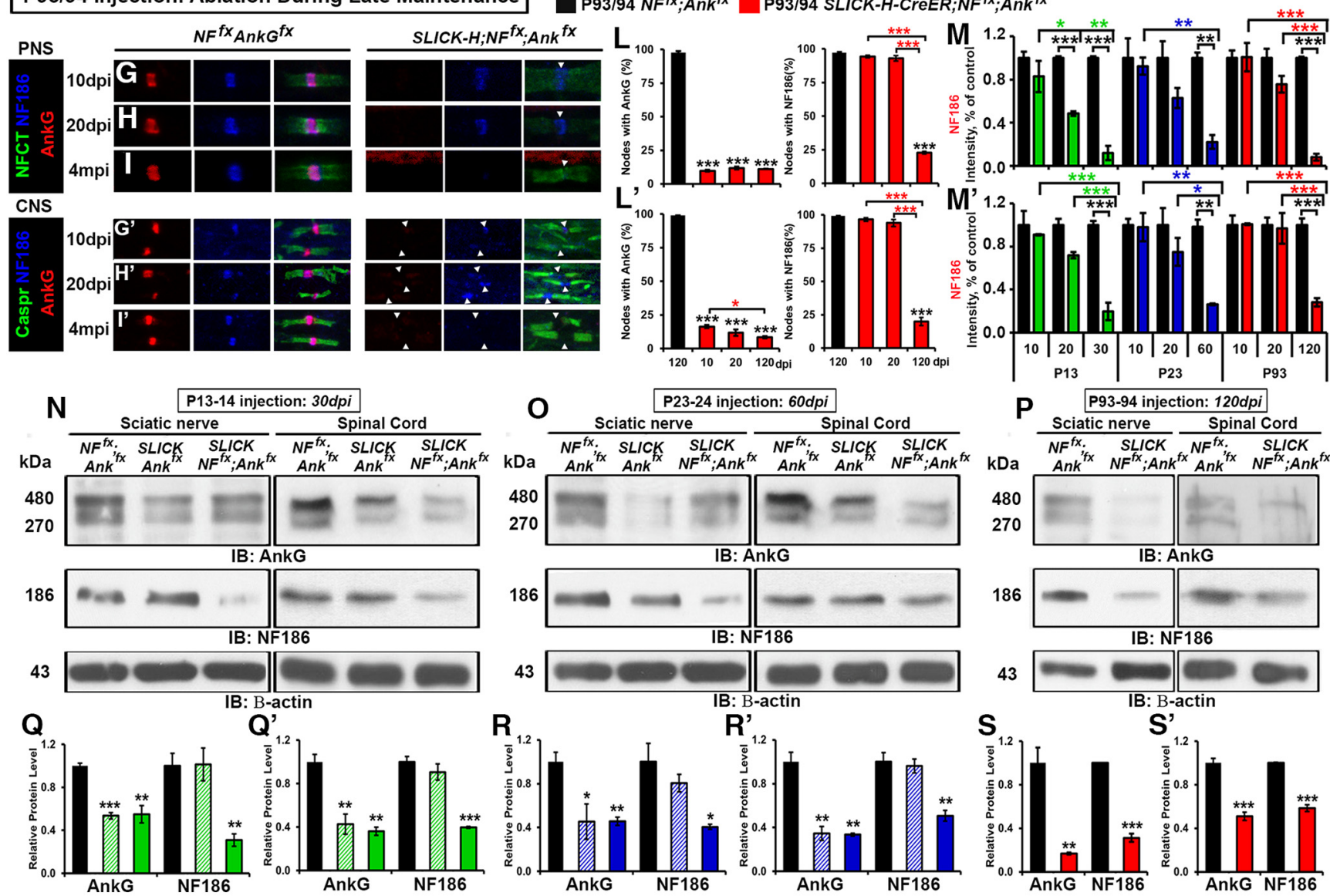

Figure 2. Combined ablation of NF186/AnkG reduces the nodal stability of AnkG and NF186. $\boldsymbol{A}-\boldsymbol{C}^{\prime}$, After tamoxifen ablation during nodal maturation (P13/14), SN fibers and SCs from $N F^{f x} ; A n k^{f x}$, SLICK-H-CreER;Ank ${ }^{f x}$, and SLICK-H-CreER;NF $F^{f x}$;Ank ${ }^{f x}$ were harvested at 10,20 , and 30 dpi. $\boldsymbol{D}-\boldsymbol{F}^{\prime}$, After tamoxifen ablation during early nodal maintenance (P23/24), SN fibers and SCs from $N F^{f x} ; A n k^{f x}$, 
continued

SLICK-H-CreER;Ank ${ }^{f x}$, and SLICK-H-CreER;NF $F^{f x} ; A n k^{f x}$ were harvested at 10, 20, and 60 dpi. G-I', After tamoxifen ablation during late nodal maintenance (P23/24), SN fibers and SCs from $N F^{f x} ; A n k^{f x}$ and SLICK-H-CreER;NF $F^{f x}$;Ank ${ }^{f x}$ were harvested at 10, 20, and 120 dpi. All SNs (A-I) were teased and immunostained with antibodies against AnkG (red), NF186 (blue), and NFCT (green); while SCs $\left(\boldsymbol{A}^{\prime}-\boldsymbol{I}^{\prime}\right)$ were immunostained with antibodies against AnkG (red), NF186 (blue), and Caspr (green). Arrowheads mark AnkG-negative nodes. $J-L^{\prime}$, Quantification of the percentage of nodes with remaining AnkG and NF186 at various time points in $N F^{f x}$;Ank ${ }^{f x}$ (black bar), SLICK-H-CreER;Ank ${ }^{f x}$ (striped green or blue bar), and SLICK-H-CreER;NFF; $A n k^{f x}$ (solid green, blue, or red bar) SN (J-L) or SC ( $\left.\boldsymbol{J}^{\prime}-\mathbf{L}^{\prime}\right)$. $\boldsymbol{M}, \boldsymbol{M}^{\prime}$, Graphs representing intensity quantification of NF186 in the SN $(\boldsymbol{M})$ and SC $\left(\boldsymbol{M}^{\prime}\right)$ nodal area of SLICK-H-CreER;NF $F^{f x} ; A n k^{f x}$ mice injected at P13/14 (green bars), P23/24 (blue bars), or P93/94 (red bars) normalized to age-matched $N F^{f x}$;Ank ${ }^{f x}$ control values (black bars). $\boldsymbol{N}-\boldsymbol{P}$, Immunoblot analysis of SN and SC lysates from $N F^{f x} ; A n k^{f x}$ littermates and SLICK-H-CreER;NF $F^{f x} ; A n k^{f x}$ mice injected at $\mathrm{P} 13 / 14$ (30 dpi), P23/24 (60 dpi), or P93/94 (120 dpi) with antibodies against AnkG, NF186, and $\beta$-actin. Q-S', Quantification of immunoblots relative to $\beta$-actin from the $\mathbf{S N}(\boldsymbol{Q}-\mathbf{S})$ or $\mathbf{S C}\left(\boldsymbol{Q}^{\prime}-\mathbf{S}^{\prime}\right)$ lysates. All data are represented as mean \pm SEM. Black asterisks indicate statistical differences between control and mutant; colored asterisks signify differences between time points among mutants. For immunostaining: $n=3-4$ mice/group; 50-100 nodes per mouse; two-way ANOVA, Tukey post hoc analysis. For immunoblots: $n=$ 3 mice; two-tailed Student's $t$ tests. Scale bar, $2 \mu \mathrm{m}$.

the nodes without detectable NF186 increased from 3.64 $\pm 0.9 \%$ at $10 \mathrm{dpi}$ to $58.6 \pm 2.1 \%$ at $30 \mathrm{dpi}$. The remaining intensity of NF186 at SC nodes 30 dpi after P13 ablation in the double AnkG/NF186 cKO was only 19.6\% compared to control levels (Fig. $2 M^{\prime}$ ). Although single NF186 cKOs were included in these analyses as was previously reported, no significant loss of NF186 or AnkG was observed before 30 dpi in either PNS or CNS (Taylor et al., 2017; data not shown). Taken together, these results demonstrate that AnkG and NF186 have differential stability at nodes of Ranvier, with AnkG being fully depleted within just 10 days of ablation, while NF186 still remained at over $30 \%$ of nodes, albeit at very low levels at $30 \mathrm{dpi}$. Futhermore, these results indicate that combined ablation of AnkG with NF186 enhances their loss at nodes of Ranvier compared to individual ablation of AnkG or NF186.

Just as after P13/14 ablation, loss of AnkG alone at P23/24 during early maintenance resulted in a significant increase in the number of nodes without AnkG over time, leading to $89.3 \pm 4.1 \%$ in the PNS and $85.2 \pm 2.7 \%$ in the CNS at 60 dpi (Fig. 2D-F, K, $D^{\prime}-F^{\prime}, K^{\prime}$ ). Likewise, ablation of AnkG/NF186 in combination at P23/24 resulted in a majority of nodes without any detectable AnkG as early as $10 \mathrm{dpi}$ in both tissues, but a gradual reduction of NF186 over time, leading to $71.8 \pm 2.4 \%$ and $72.5 \pm 0.5 \%$ of nodes with no detectable NF186 at 60 dpi in the PNS and CNS, respectively (Fig. $2 K, K^{\prime}$ ). Consistently, the intensity levels of NF186 gradually decreased to $22.2 \%$ in SN and $26.2 \%$ in SC at $60 \mathrm{dpi}$ in the PNS and CNS, respectively, compared to controls (Fig. 2M, $M^{\prime}$ ). After P93/94 ablation during late maintenance, the level of nodes with undetectable AnkG was already significant in double AnkG/NF186 cKO by 10 dpi in both SN and SC; however, in SC, there were more AnkG-deficient nodes from $82.6 \pm 1.3 \%$ at 10 dpi to $90.7 \pm 0.8 \%$ at $30 \mathrm{dpi}$ (Fig. $2 G-l, L, G^{\prime}-l^{\prime}, L^{\prime}$ ). In both SN and SC, the number of nodes without NF186 remained insignificant at control levels until $20 \mathrm{dpi}$ and then gradually reached to $75.6 \pm 0.9 \%$ and $79.4 \pm 2.9 \%$ by 120 dpi, respectively (Fig. $2 L, L^{\prime}$ ).

As further verification of the ablation of AnkG and NF186, immunoblots were performed in SC and SN at the final time points: 30 dpi after P13/14 ablation, 60 dpi after P23/24 ablation, and 120 dpi after P93/94 ablation (Fig. $2 N-P)$. When immunoblots were quantified, SLICK-H;
$A n k^{f x}$ single cKO showed a significant reduction in the levels of AnkG compared to age-matched control levels in both SN (Fig. 2Q, $R$ ) and SC (Fig. 2Q', $R^{\prime}$ ), but no significant change in the levels of NF186 compared to controls. In contrast, all double SLICK-H;NF ${ }^{f x} A n K^{f x}$ display significant loss of both AnkG and NF186 regardless of the timing of injection in both the PNS (Fig. 2Q-S) and CNS (Fig. 2Q'-S' ). Although the trends in reduction of AnkG and NF186 levels between P13/14, P23/24, and P93/94 ablation were ultimately the same, overall, delaying the timeline of ablation led to a longer half-life of NF186 in the double cKOs, which was consistent with the delay of the ataxic phenotype seen in P93/94 compared to $\mathrm{P} 23 / 24$ and $\mathrm{P} 13 / 14$ ablated double cKOs.

\section{Timing of AnkG and NF186 ablation has differential effects on sodium channel destabilization in the CNS and PNS}

To determine the consequences of the combined loss of AnkG and NF186 on the maturation and maintenance of the nodal region, teased SNs from controls and double AnkG/NF186 cKOs at various time points postinjection were triple immunostained with antibodies against pan$\mathrm{Na}_{V}$ (red), NF186 (blue), and NFCT (Fig. 3A-l). At $10 \mathrm{dpi}$, when NF186 was still present at the nodes without any appreciable loss in double AnkG/NF186 cKOs, there were no changes in either the localization or intensity of pan$\mathrm{Na}_{\mathrm{V}}$ channels in the PNS, no matter if ablation was performed at P13/14, P23/24, or P93/94 (Fig. 3A, D, G, S). By 20 dpi after P13/14 ablation of AnkG/NF186, when NF186 was undetectable in $26.3 \%$ of SN nodes and had dropped to an intensity below $50 \%$, the level of $\mathrm{Na}_{\mathrm{V}}$ channels was similarly reduced to $55.5 \%$ of the control intensity (Fig. $3 B, S)$. Consistently, at 20 dpi after P23/24 and P93/94 ablation, the intensity of $\mathrm{Na}_{\mathrm{V}}$ channels in double AnkG/ NF186 cKOs was significantly reduced to $48.8 \%$ and $47.6 \%$ of the aged matched control, respectively (Fig. 3E, $H, S)$. Scoring nodes with no detectable pan- $\mathrm{Na}_{\mathrm{V}}$ at $30 \mathrm{dpi}$ after P13/14 ablation, 60 dpi after P23/24, and 120 dpi after $\mathrm{P} 93 / 94$ revealed a $21.8 \pm 4.4 \%, 40.6 \pm 4.1 \%$, and $28.7 \pm 7.7 \%$ reduction in the double cKOs compared to matched controls, respectively; likewise, the intensity levels for pan- $\mathrm{Na}_{\mathrm{v}}$ at nodes in double cKOs dropped below $30 \%$ of control levels at these terminal time points (Fig. $3 C, F, I, S)$. Together, these data indicate that combined 

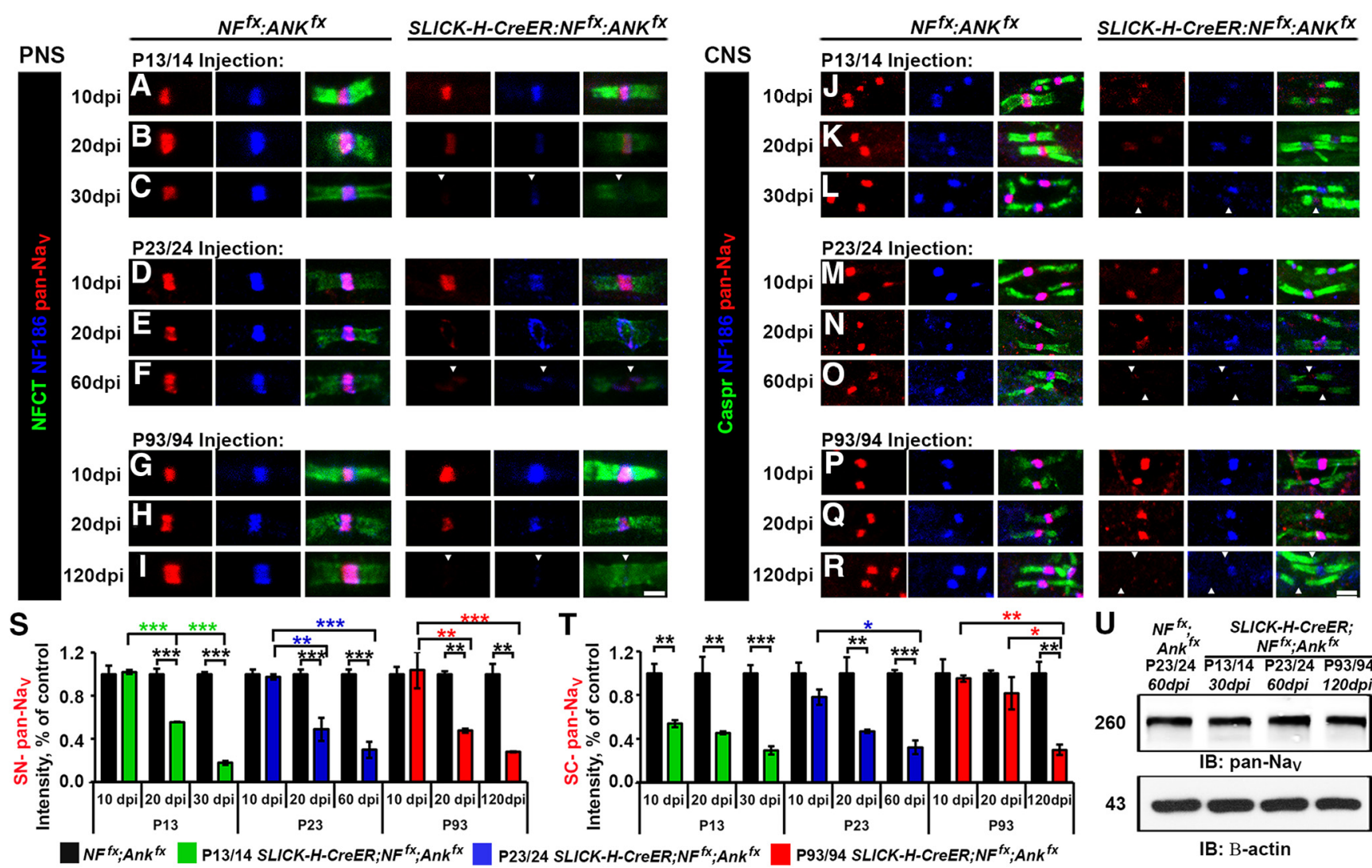

IB: B-actin

Figure 3. Timing of NF186/AnkG ablation alters stability of sodium channels in the CNS. A-I, SN fibers from $N F^{f x}$;Ank ${ }^{f x}$ and SLICK-H-CreER;NF ${ }^{f x}$;Ank ${ }^{f x}$ littermates injected at P13/14 (A-C, 10-30 dpi), P23/24 (D-F, 10-60 dpi), or P93/94 (G-I, 10-120 dpi)

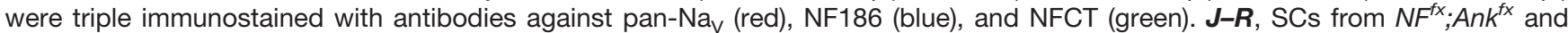
SLICK-H-CreER;NF ${ }^{f x}$;Ank ${ }^{f x}$ littermates injected at P13/14 (J-L, 10-30 dpi), P23/24 (M-O, 10-60 dpi), or P93/94 (P-R, 10-120 dpi) were triple immunostained with antibodies against pan-Na $($ red), NF186 (blue), and Caspr (green). $\mathbf{S}, \boldsymbol{T}$, Graphs representing intensity quantification of pan-Na $\mathrm{Na}_{\mathrm{V}}$ in the SN (S) and SC $(\boldsymbol{T})$ nodal area of SLICK-H-CreER;NF ${ }^{f x} ; A n k^{f x}$ mice injected at P13/14 (green bars), $\mathrm{P} 23 / 24$ (blue bars), or P93/94 (red bars) normalized to age-matched $N F^{f x}$; Ank ${ }^{f x}$ control values (black bars). $\boldsymbol{U}$, Immunoblot analysis of SC lysates from $60 \mathrm{dpi} N F^{f x} ; A n k^{f x}$ injected at P23/24 compared to SLICK-H-CreER;NF $F^{f x} ; A n k^{f x}$ mice injected at P13/14 (30 dpi), P23/24 (60 dpi), or P93/94 (120 dpi) with antibodies against pan-Na $\mathrm{N}_{\mathrm{V}}$ and $\beta$-actin. Arrowheads mark NF186-negative nodes. All data are represented as mean \pm SEM ( $n=3-4$ mice/group; $50-100$ nodes per mouse; two-way ANOVA, Tukey post hoc analysis). Black asterisks indicate statistical differences between control and mutant; colored asterisks signify differences between time points among mutants. Scale bar, $2 \mu \mathrm{m}$.

ablation of AnkG and NF186 leads to a rapid reduction of $\mathrm{Na}_{V}$ channels in the PNS, which is evident by $20 \mathrm{dpi}$ despite the timing of ablation. This suggests that disruption of $\mathrm{Na}_{V}$ channels at least in the PNS is highly influenced by the loss of AnkG, which falls to below $10 \%$ by just $10 \mathrm{dpi}$ and to a lesser extent NF186, which takes longer to dissipate from the node and varies depending on the timing of ablation.

To further study the effects of ablating AnkG and NF186 during nodal maturation versus maintenance in the CNS, SCs from double AnkG/NF186 cKOs and littermate controls were also immunostained with antibodies against pan-Na $\mathrm{N}_{\mathrm{V}}$ (red), NF186 (blue), and paranodal Caspr (Fig. $3 J-R)$. At $10 \mathrm{dpi}$, when just as in $\mathrm{SN}$, there was no appreciable loss of NF186 from the SC of double AnkG/ NF186 cKOs, there was, however, a significant reduction in the intensity level of $\mathrm{Na}_{V}$ channels after $\mathrm{P} 13 / 14$ ablation at $53.8 \%$, but not at $\mathrm{P} 23 / 24$ or $\mathrm{P} 93 / 94$ which remained at $78.1 \%$ and $95.3 \%$, respectively (Fig. $3 J, M, P, T$ ). By 20 $\mathrm{dpi}$, a significant reduction in intensity between controls and double cKO was seen after ablation of NF186 and AnkG at P13/14 and P23/24, but not at P93/94 (Fig. 3J, M, $P, T)$. It is not until the final time point of $120 \mathrm{dpi}$ after ablation of NF186 and AnkG at P93/94 that a significant reduction in the intensity of $\mathrm{Na}_{V}$ channels to below $30 \%$ is seen in the double cKO compared to controls (Fig. $3 R, T$ ). 30 dpi after P13/14 ablation and 60 dpi after P23/24 give similar reductions in $\mathrm{Na}_{\mathrm{V}}$ channel intensity to $\sim 29.1 \%$ and $32 \%$ of control values in CNS (Fig. $3 L, O, T$ ). At these terminal time points in the CNS, there is also a significant decrease in the number of nodes with detectable pan- $\mathrm{Na}_{\mathrm{V}}$ compared with controls to $58.2 \pm 2.5 \%$ at $30 \mathrm{dpi}$ after P13/14 ablation, $52.8 .8 \pm 4.7 \% 60 \mathrm{dpi}$ after P23/24, and $34.3 \pm 2.3 \% 120 \mathrm{dpi}$ after P93/94. Despite the pronounced decrease of pan- $\mathrm{Na}_{\mathrm{V}}$ levels at the nodes in SLICK-H;NF ${ }^{f x ;} A n k^{f x} S C$, there were no significant changes in the total protein levels of pan- $\mathrm{Na}_{\mathrm{V}}$ channels normalized to $\beta$-actin compared to $N F^{f x} ; A n k^{f x}$ controls (Fig. $3 U$ ). Taken together, these data suggest that while the total level of $\mathrm{Na}_{V}$ channel is not decreased in the SC, $\mathrm{Na}_{V}$ 


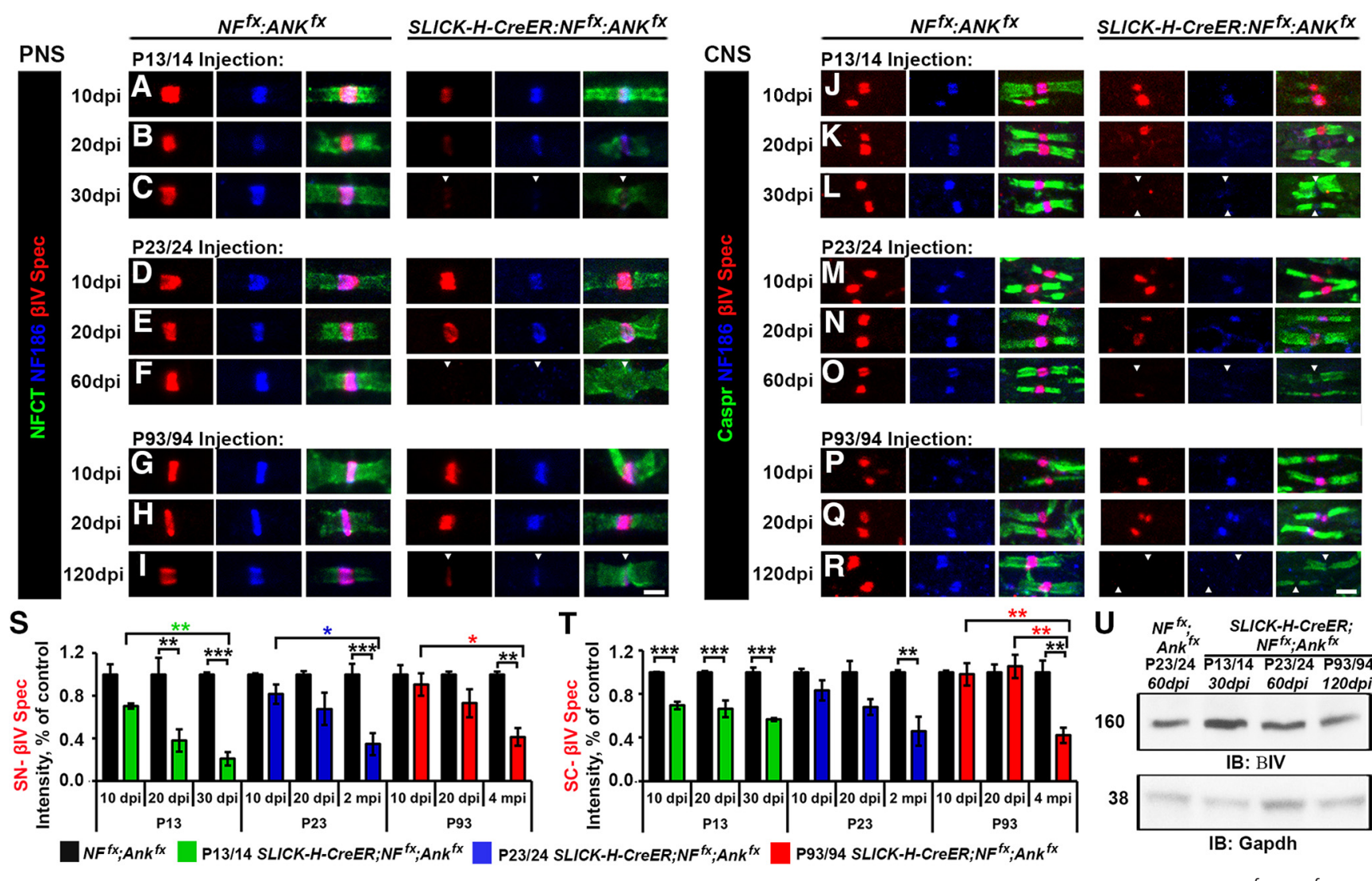

Figure 4. Nodal stability of $\beta$ IV Spectrin is altered by the timing of NF186/AnkG ablation. A-I, SN fibers from $N F^{f x}$;Ank ${ }^{f x}$, and SLICK-H-CreER;NF ${ }^{f x}$;Ank ${ }^{f x}$ littermates injected at P13/14 (A-C, 10-30 dpi), P23/24 (D-F, 10-60 dpi), or P93/94 (G-I, 10-120 dpi) were triple immunostained with antibodies against $\beta$ IV Spectrin (red), NF186 (blue), and NFCT (green). J-R, SCs from $N F^{f x}$;Ank ${ }^{f x}$ and SLICK-H-CreER;NF ${ }^{f x}$;Ank ${ }^{f x}$ littermates injected at P13/14 (J-L, 10-30 dpi), P23/24 (M-O, 10-60 dpi), or P93/94 (P-R, 10-120 dpi) were triple immunostained with antibodies against $\beta$ IV Spectrin (red), NF186 (blue), and Caspr (green). S, T, Graphs representing intensity quantification of $\beta$ IV Spectrin in the SN (S) and SC $(\boldsymbol{T})$ nodal area of SLICK-H-CreER;NF $F^{f x}$;Ank ${ }^{f x}$ mice injected at P13/14 (green bars), P23/24 (blue bars), or P93/94 (red bars) normalized to age-matched $N F^{f x}$;Ank ${ }^{f x}$ control values (black bars). $\boldsymbol{U}$, Immunoblot analysis of SC lysates from $60 \mathrm{dpi} N F^{f x}$;Ank ${ }^{f x}$ injected at P23/24 compared to SLICK-H-CreER;NF ${ }^{f x}$;Ank ${ }^{f x}$ mice injected at P13/14 (30 dpi), P23/24 (60 dpi), or P93/94 (120 dpi) with antibodies against $\beta$ IV Spectrin and Gapdh. Arrowheads mark NF186-negative nodes. All data are represented as mean \pm SEM ( $n=3-4$ mice/group; $50-100$ nodes per mouse; two-way ANOVA, Tukey post hoc analysis). Black asterisks indicate statistical differences between control and mutant; colored asterisks signify differences between time points among mutants. Scale bar, $2 \mu \mathrm{m}$.

channel does not maintain clustering at the node without the anchoring to cytoskeletal scaffold by AnkG, and the cell adhesion molecule, NF186. In addition, timing of ablation strongly influences the rate at which $\mathrm{Na}_{\mathrm{V}}$ levels are lost from nodes in SC but not in $\mathrm{SN}$, which may indicate that NF186 plays a greater role of anchoring $\mathrm{Na}_{\mathrm{V}}$ levels in the CNS and is likely reflective of different extracellular binding partners between the PNS and CNS.

\section{$\beta$ IV spectrin stability at the nodes increases with age}

To thoroughly elucidate the impact of timing of ablation of AnkG and NF186 on nodal stabilization, teased SNs and SC slices from controls and double AnkG/NF186 cKOs at various time points postinjection were also triple immunostained with antibodies against $\beta$ IV Spectrin (red), NF186 (blue), and NFCT or Caspr (green) in SN (Fig. 4A-l) and SC (Fig. 4J-R), respectively. At just $10 \mathrm{dpi}$ after ablation at $\mathrm{P} 13 / 14$ when there is complete loss of AnkG but not yet loss of NF186 in double cKO, a trend toward a reduction in intensity of $\beta$ IV Spectrin at SN nodes (70.2 $\pm 2.4 \%$ ) and already a significant difference at SC nodes $(69.5 \pm 3.4 \%)$ is observed compared to controls (Fig. $4 A$, $J, S, T)$. While in $\mathrm{SN}$ there is further reduction in $\beta \mathrm{IV}$ Spectrin intensity by $20 \mathrm{dpi}$ to $38.3 \%$ and $30 \mathrm{dpi}$ to $21.0 \%$, in SC after $\mathrm{P} 13 / 14$ ablation there is no additional decrease in the intensity, which remains at $56.5 \%$ of control values at $30 \mathrm{dpi}$ (Fig. 4B, C, K, L, S). Although there was not a significant loss of $\beta$ IV Spectrin intensity over time after $\mathrm{P} 13 / 14$ ablation in SC, there was a significant decrease in the number of nodes with detectable levels of $\beta$ IV Spectrin in both PNS and CNS to $63.9 \pm 2.8$ and $76.1 \pm 4.5 \%$ by 30 dpi (Fig. $4 K, L$ ).

In contrast to ablation during nodal maturation, loss of NF186 with AnkG during either early or late nodal maintenance resulted in no significant changes in either the localization or intensity $\beta$ IV Spectrin at 10 or $20 \mathrm{dpi}$ in either tissue (Fig. 4D-T). Only at 60 dpi after P23/24 and 120 dpi after P93/94 ablation of NF186 and AnkG was a significant reduction detected in $\beta \mathrm{IV}$ intensity compared 

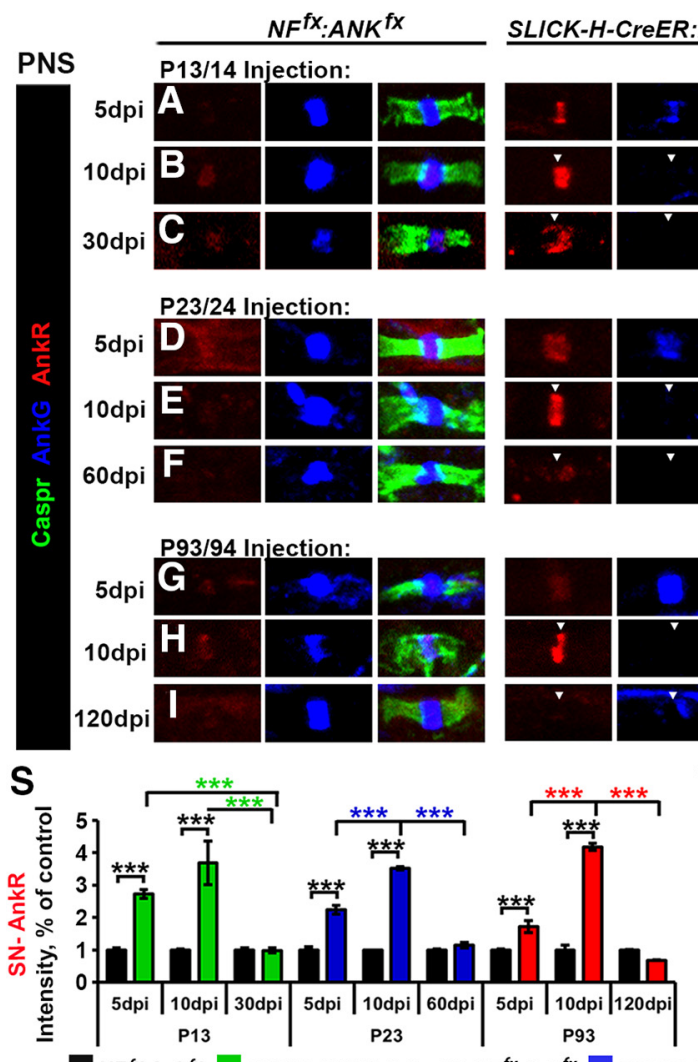

SLICK-H-CreER:NFfX:ANK fX
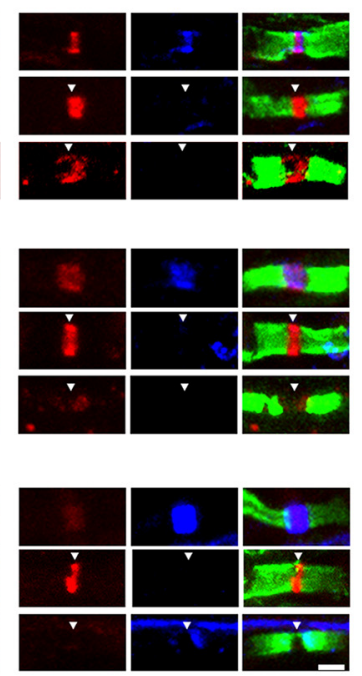

CNS

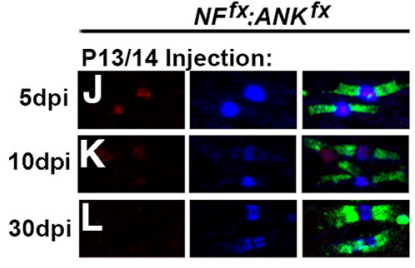

P23/24 Injection: $5 \mathrm{dpi}$

$10 \mathrm{dpi} \mathbf{N}$
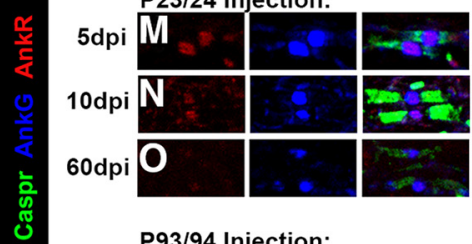
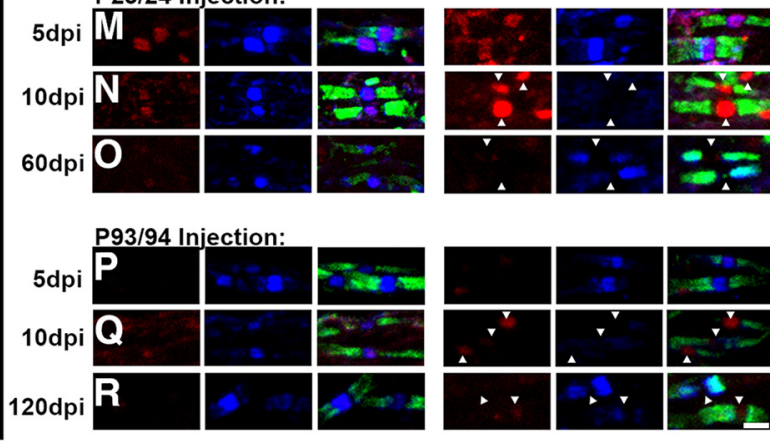

$\mathbf{T}$
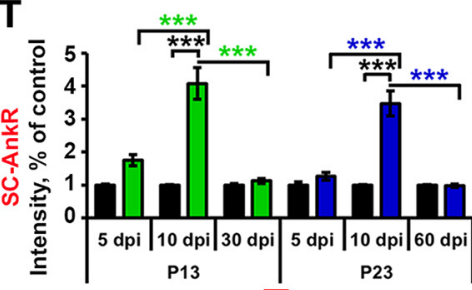
P23

P93/94 SLICK-H-CreER;NF ${ }^{f x}$;Ank ${ }^{f x}$
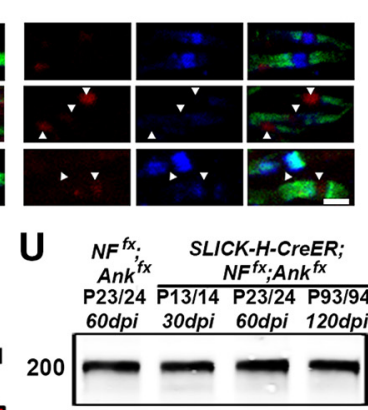

IB: AnkR

43

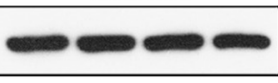

IB: B-actin

Figure 5. Combined ablation of NF186/AnkG reveals that AnkR fails to sustain nodal stability. A-I, PNS fibers from $N F^{f x}$;Ank ${ }^{f x}$ and SLICK-H-CreER;NF ${ }^{f x}$;Ank ${ }^{f x}$ littermates injected at P13/14 (A-C, 5-30 dpi), P23/24 (D-F, 5-60 dpi), or P93/94 (G-I, 5-120 dpi) were triple immunostained with antibodies against AnkR (red), NF186 (blue), and NFCT (green). J-R, SCs from NF $F^{f x}$;Ank ${ }^{f x}$ and SLICK-HCreER;NF ${ }^{f x} ; A n k^{f x}$ littermates injected at P13/14 (J-L, 5-30 dpi), P23/24 (M-O, 5-60 dpi), or P93/94 (P-R, 5-120 dpi) were triple immunostained with antibodies against AnkR (red), NF186 (blue), and Caspr (green). $\boldsymbol{S}, \boldsymbol{T}$, Graphs representing intensity quantification of AnkR in the PNS (S) and CNS (T) nodal area of SLICK-H-CreER;NF ${ }^{f x}$;Ank ${ }^{f x}$ mice injected at P13/14 (green bars), P23/24 (blue bars), or P93/94 (red bars) normalized to age-matched $N F^{f x}$;Ank ${ }^{f x}$ control values (black bars). $\boldsymbol{U}$, Immunoblot analysis of SC lysates from 60 dpi $N F^{f x}$;Ank ${ }^{f x}$ injected at P23/24 compared to SLICK-H-CreER;NF $F^{f x}$;Ank ${ }^{f x}$ mice injected at P13/14 (30 dpi), P23/24 (60 dpi), or P93/94 (120 dpi) with antibodies against AnkR and $\beta$-actin. Arrowheads mark Ank-G negative nodes. All data are represented as mean \pm SEM ( $n=3-4$ mice/group; 50-100 nodes per mouse; two-way ANOVA, Tukey post hoc analysis). Black asterisks indicate statistical differences between control and mutant; while colored asterisks signify differences between time points among mutants. Scale bar, $2 \mu \mathrm{m}$.

to controls (Fig. 4F, I, O, R-T). At these terminal time points, there was also a reduction in the number of nodes with detectable $\beta$ IV Spectrin in both SN $(62.7 \pm 5.9$ and $56.1 \pm 4.0 \%)$ and SC $(60.3 \pm 7.9$ and $49.6 \pm 12.9 \%)$ for $\mathrm{P} 23 / 24$ and P93/94 ablation, respectively. Although the levels of nodal $\beta$ IV Spectrin were reduced, there was no significant reduction in the total protein levels of $\beta \mathrm{IV}$ in SLICK-H;NF ${ }^{f x} A n k^{f x}$ SC when normalized to GAPDH compared to $N F^{f x} ; A n k^{f x}$ controls at the terminal time point for P13/14, P23/24, and P93/94 ablation (Fig. 4U). Consistently, no reduction in total $\beta$ IV Spectrin protein levels was seen in single AnkG or NF186 cKO which was previously reported for P23 injections (Saifetiarova et al., 2017; Taylor et al., 2017). Together these results show that the stability of $\beta$ IV Spectrin in the nodal complex is dependent on interactions between both the cytoskeletal competent AnkG and the cell adhesion molecule NF186, as well as on the timing of ablation in either maturation or maintenance stages.

\section{AnkR is not sufficient to maintain nodal stability without AnkG and NF186}

Previously, loss of AnkG at the node was found to lead to a dramatic increase in Ankyrin $\mathrm{R}$ (AnkR), a resident nodal protein (Ho et al., 2014; Saifetiarova et al., 2017); however, when NF186 was ablated, a significant reduction in the level of AnkR was observed (Taylor et al., 2017). As our current model double AnkG/NF186 cKOs reflects loss of both proteins, we next determined what the consequences of ablating both AnkG and NF186 at different time windows would have on AnkR levels. PNS and CNS nerves from controls and double AnkG/NF186 cKOs at various time points postinjection were immunostained with antibodies against AnkR (red), AnkG (blue), and Caspr (green; Fig. 5). As AnkG is already depleted by 10 dpi after P13/14, P23/24, and P93/94 ablation of AnkG/ NF186 in both PNS and CNS (Fig. 2), these studies were started at 5 dpi to capture a time point before AnkG has completely moved out of the node. Interestingly, at $5 \mathrm{dpi}$ 
in both PNS and CNS, the levels of AnkG varied with timing of ablation, so that there was less remaining AnkG with $\mathrm{P} 13 / 14$ ablation compared to P23/24 and even less compared to P93/94 which appeared to be at control levels (Fig. 5A-R).

In the PNS at $5 \mathrm{dpi}$, AnkR levels quickly increased to compensate as AnkG was being depleted from the node, which is reflected by a 2.73-fold increase in AnkR levels after P13/14, 2.25-fold after P23/24, and 1.72-fold after P93/94 (Fig. 5A, D, G, S). By $10 \mathrm{dpi}$, as AnkG levels reached $<10 \%$, the intensity of AnkR continued to rise to $>3.5$-fold compared to control in all ablation schemes (Fig. 5B, E, H, S). At the terminal time points when not only AnkG but also NF186 is depleted from the node, AnkR levels fell back to or even below control levels (Fig. 5C, F, I, S). In addition, there was a reduction in the number of AnkR-positive nodes compared to controls to $86.1 \pm$ $2.7 \%$ at $\mathrm{P} 30$ after $\mathrm{P} 13 / 14$ ablation, to $85.7 \pm 2.5 \%$ at $\mathrm{P} 60$ after P23/24 ablation, and to $74.8 \pm 0.9 \%$ at $\mathrm{P} 120$ after P93/94 ablation. In contrast to PNS, AnkR took longer to move into the nodes after AnkG was lost, which was reflected by no significant increase in AnkR intensity at 5 $\mathrm{dpi}$, although there was a trend with a 1.75-fold increase compared to controls at $5 \mathrm{dpi}$ after $\mathrm{P} 13 / 14$ ablation of NF186 and AnkG (Fig. 5J, M, P, T). At $10 \mathrm{dpi}$, AnkR intensity levels had significantly increased to 4.1 -fold after $\mathrm{P} 13 / 14$, 3.5-fold after P23/24, and 2.7-fold after P93/94 compared to age-matched controls (Fig. $5 K, N, Q, T$ ). Just as in PNS, AnkR levels fell back to around control values by the final time point in SC whether ablation of AnkG/ NF186 had occurred at P13/14, P23/24, or P93/94 (Fig. $5 L, O, R, T)$. There were also very similar reductions in the number of AnkR-positive nodes compared to controls between PNS and CNS, with $85.6 \pm 1.3 \%$ at P30 after $\mathrm{P} 13 / 14$ ablation, $83.6 \pm 2.1 \%$ at $\mathrm{P} 60$ after P23/24 ablation, and $71.8 \pm 4.3 \%$ at $\mathrm{P} 120$ after P93/94 ablation. Not surprisingly, due to the minimal loss of AnkR compared to controls at the final time point, there was neither a significant increase nor decrease in total protein levels of AnkR in SLICK-H;NF ${ }^{f x}$; Ank ${ }^{f x} S C$ normalized to $\beta$-actin compared to $N F^{f x}$;Ank ${ }^{f x}$ controls (Fig. 5U). Taken together, these data provide evidence that despite the dynamic range of AnkR at the node as it compensates for AnkG loss, AnkR is unable to maintain the nodal complex without AnkG and NF186, and ultimately it begins to destabilize just as is the case for $\mathrm{Na}_{\mathrm{V}}$ channels and $\beta \mathrm{IV}$ Spectrin.

\section{Decline in nerve conduction follows timelines of nodal destabilization}

As changes in the electrophysiological properties of myelinated axons were previously reported after ablation of NF186 or AnkG alone in neurons (Desmazieres et al., 2014; Saifetiarova et al., 2017; Taylor et al., 2017), we next wanted to determine the consequences on nerve conduction of simultaneous ablation of NF186 with AnkG at various time points in nodal development. Thus, we performed in vivo electrophysiological recordings from the $\mathrm{SN}$ of age-matched controls and double AnkG/NF186 cKOs mice which were ablated at various time points: maturation $(\mathrm{P} 13 / 14)$, early maintenance $(\mathrm{P} 23 / 24)$, or late maintenance (P93/94; Fig. 6). As early as $10 \mathrm{dpi}$ after $\mathrm{P} 13 / 14$ ablation during nodal maturation, a significant decrease in NCV was already apparent in SLICK-H;NF ${ }^{f x}$; $A n k^{f x}$ compared to $N F^{f x}$; $A n k^{f x}$ controls, and this reduced NCV persisted until 30 dpi (Fig. 6A, B). As is evident from the $N F^{f x}$; $A n k^{f x}$ controls (black bars), as mice age there is naturally an increase in both the compound action potential (CAP) amplitude (Fig. 6C), as well as a more gradual increase in the NCVs (Fig. 6E). However, this same increase was not found in the double cKO after P13/14 ablation, and instead a significant decrease was seen in the CAP amplitude compared to age-matched controls (Fig. 6C).

While P13/14 ablation led to changes at $10 \mathrm{dpi}$, no changes in either conduction velocity or CAP amplitude were seen in SLICK-H;NF $F^{f x ;} A n k^{f x}$ compared to $N F^{f x} ; A n k^{f x}$ controls $10 \mathrm{dpi}$ after ablation at P23/24 during early nodal maintenance (Fig. 6D-F). By 20 dpi after P23/24 ablation, there was a significant reduction in both NCV and amplitude in double cKO compared to control, which continued at $60 \mathrm{dpi}$. This is in contrast with both single AnkG and NF186 CKO, which were previously shown to have no reduction in either NCV or amplitude of SN before $4 \mathrm{mpi}$ after ablation at P23/24 (Saifetiarova et al., 2017; Taylor et al., 2017). When AnkG and NF186 were ablated during late nodal maintenance at P93/94, no significant changes in NCV were detected before $60 \mathrm{dpi}$; although there was a trend toward lower CAP amplitudes at this time point (Fig. 6G-I). However, at the terminal time point of $120 \mathrm{dpi}$ after P93/94 ablation, when very little NF186 remains at the nodes, there was a significant reduction in both NCV and CAP amplitude observed in the double cKO compared to age-matched controls. This loss of NCV in the SN after P93/94 ablation of NF186 and AnkG is consistent both with reductions seen $30 \mathrm{dpi}$ after $\mathrm{P} 13 / 14$ and $60 \mathrm{dpi}$ after P23/24 dual ablation and with the decrease seen 6 mpi after P23 ablation of single NF186, but not single ablation of AnkG, which only led to a decrease in amplitude. However, loss of AnkG with NF186 led to changes in NCV at 10 dpi before NF186 levels at the node had dropped. Taken together, these electrophysiological measurements support a synergistic role for NF186 and AnkG in maintaining sufficient levels of $\mathrm{Na}_{v}$ channels at nodes to propagate action potentials and sustain proper conduction velocity along myelinated axons. Furthermore, these studies emphasize that delaying the timing of ablation can preserve the integrity of the nodal complex and thereby sustain the electrical properties of myelinated axons for some time. However, NF186 levels falling below critical levels at the node triggers severe nodal degeneration and thus loss of nerve conduction.

\section{Enhanced destabilization of the nodal complex leads to faster ultrastructural changes in myelinated axons}

As ablation of NF186 in combination with AnkG led to accelerated nodal disorganization and reduction in nerve conduction compared to single lines, we next inspected if the ultrastructural pathology of myelinated axons was also enhanced in this double ablation model. At $60 \mathrm{dpi}$ after P23/24 ablation of NF186 and AnkG, SNs and SCs 

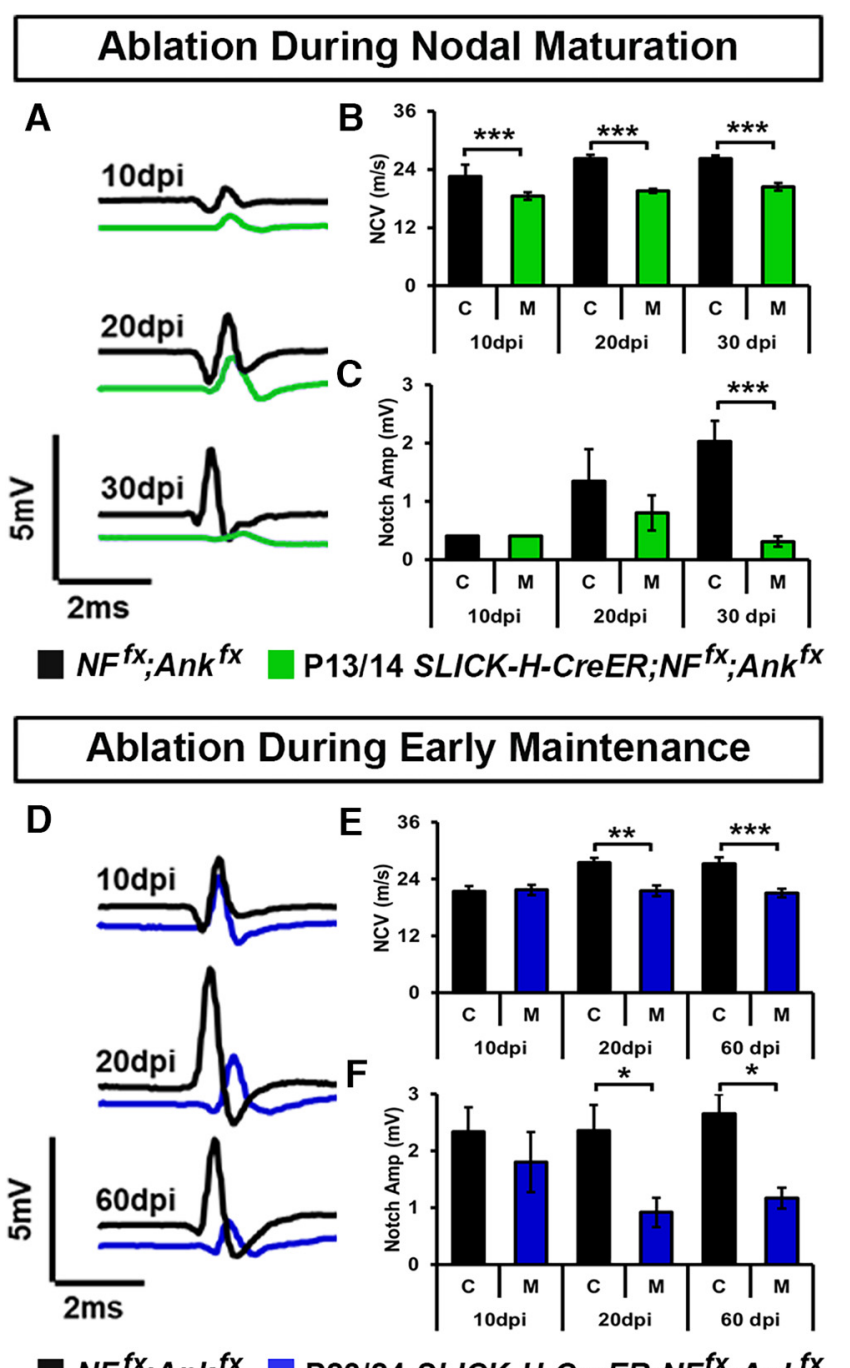

- NF ${ }^{f x} ; A n k^{f x} \square \mathrm{P} 23 / 24$ SLICK-H-CreER;NF ${ }^{f x} ; A n k^{f x}$

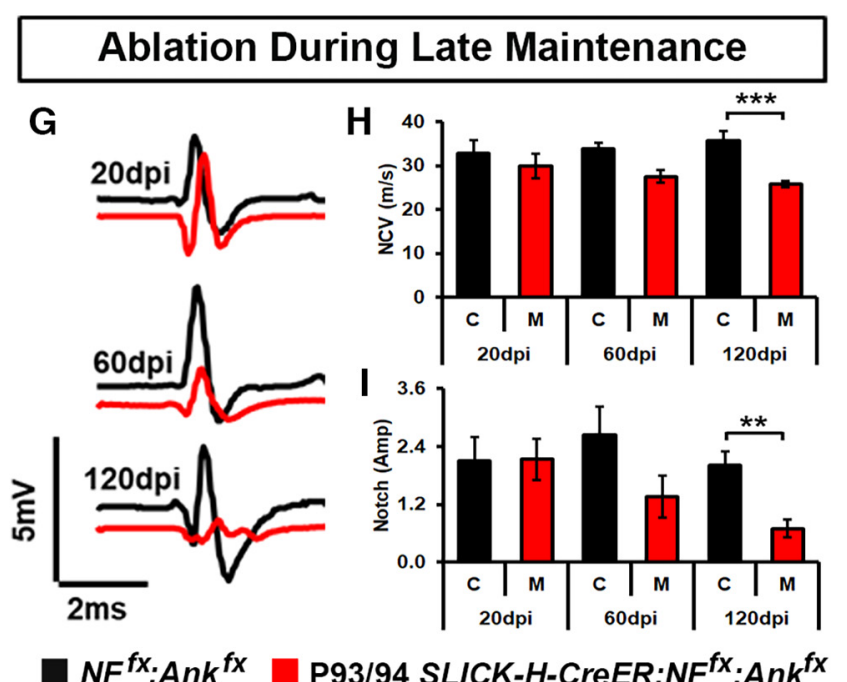

Figure 6. Combined loss of neurofascin 186 and AnkG severely impacts nerve conduction. $\boldsymbol{A}-\boldsymbol{C}$, Representative electrophysiological profiles $(\boldsymbol{A})$ of compound action potentials (CAPs) from SNs 10, 20, and 30 days after tamoxifen injection during nodal maturation $(\mathrm{P} 13 / 14)$ for $N F^{f x} ; A n k^{f x}$ (black line) and SLICK-H-
Figure 6. continued

CreER;NF $F^{f x} ; A n k^{f x}$ (green line) with quantification of NCV $(\boldsymbol{B})$ and amplitude $(\boldsymbol{C})$. $\boldsymbol{D}-\boldsymbol{F}$, Representative electrophysiological profiles (D) of CAPs from SNs 10, 20, and 60 days after tamoxifen injection during early nodal maintenance (P23/24) for $N F^{f x}$; $A n k^{f x}$ (black line) and SLICK-H-CreER;NF ${ }^{f x} ; A n K^{f x}$ (blue line) with quantification of NCV $(\boldsymbol{E})$ and amplitude $(\boldsymbol{F})$. G-I, Representative electrophysiological profiles (G) of CAPs from SNs of 10, 60, and 120 days after tamoxifen injection during late nodal maintenance (P93/94) for $N F^{f x} ; A n k^{f x}$ (black line) and SLICK-H-CreER;NF $F^{f x}$; $A n k^{f x}$ (blue line) with quantification of NCV $(\boldsymbol{H})$ and amplitude (I). All data are represented as mean \pm SEM $(n=6-8$ mice/group; two-way ANOVA, Tukey post hoc analysis). Black asterisks indicate statistical differences between control and mutant; colored asterisks signify differences between time points among the mutant group.

from $N F^{f x} ; A n k^{f x}$ and $S L I C K-H ; N F^{f x ;} A n k^{f x}$ were processed for electron microscopy under identical conditions; representative images are presented in Figs. 7 and 8, respectively. To closely assess the integrity of the axons, electron micrographs of cross sections through the $\mathrm{SN}$ from P23/24 injected controls and the dual cKO were evaluated (Fig. $7 A-J$ ). The transverse sections from P23/24 injected control SN show morphologically normal axons (green arrowhead) surrounded by compact myelin ensheathment (green arrows, Fig. $7 A, C$ ). While roughly $50 \%$ of myelinated axons in the SNs of dual cKOs showed no significant differences in myelin thickness or axon diameter compared to controls, the remaining myelinated fibers from P23/24 ablated SLICK-H;NF $F^{f x} A n k^{f x}$ displayed signs of axonal pathology (Fig. $7 B, D-J)$. The most frequent axonal morphology observed was axonal atrophy, where the axons are clearly too small for their surrounding myelin sheath (Bilbao and Schmidt, 2014). This axonal shrinking, which is represented in several dual ablated axons in Fig. 7B, $D-F, J$, was accompanied by abnormalities in the periaxonal region including swellings (red arrowheads), myelin structural alterations (red arrows), or vacuolation (red asterisks). Further, accumulations of debris and disordered presence of organelles was observed in $\sim 10 \%$ of SLICK-H;NF $F^{f x} A n k^{f x}$ axons (Fig. $7 E, G$ ), while vacuolation within the axons was found at a frequency $<5 \%$ in dual mutant SN but never observed in controls (Fig. 7B, J). Electron micrographs of longitudinal sections through the nodal/paranodal regions of SN from P23/24 injected controls and the dual cKO showed preservation of stereotypical axo-glial domains (Fig. $7 K-L^{\prime}$ ). In addition, accumulations of membranous debris and organelles were consistently found at SLICK-H;N $F^{f x ;} A n k^{f x}$ nodes (Fig. $7 L-L^{\prime}$ ), which were rarely observed in control fibers (Fig. $7 K$ ) suggesting axonal cytoskeletal disorganization in the nodal regions. At higher magnification, the paranodal myelin loops from the dual cKO mice (black arrowheads, Fig. $7 \mathrm{~N}$ ) showed normal morphology of tightly apposed myelin loops that indent the axons with characteristic electrondense septa, as was observed in control mice (black arrowheads, Fig. $7 M$ ) indicating that the uniform arrangement of septa between the myelin loops and the axolemma were maintained in mutant axons in the PNS. 

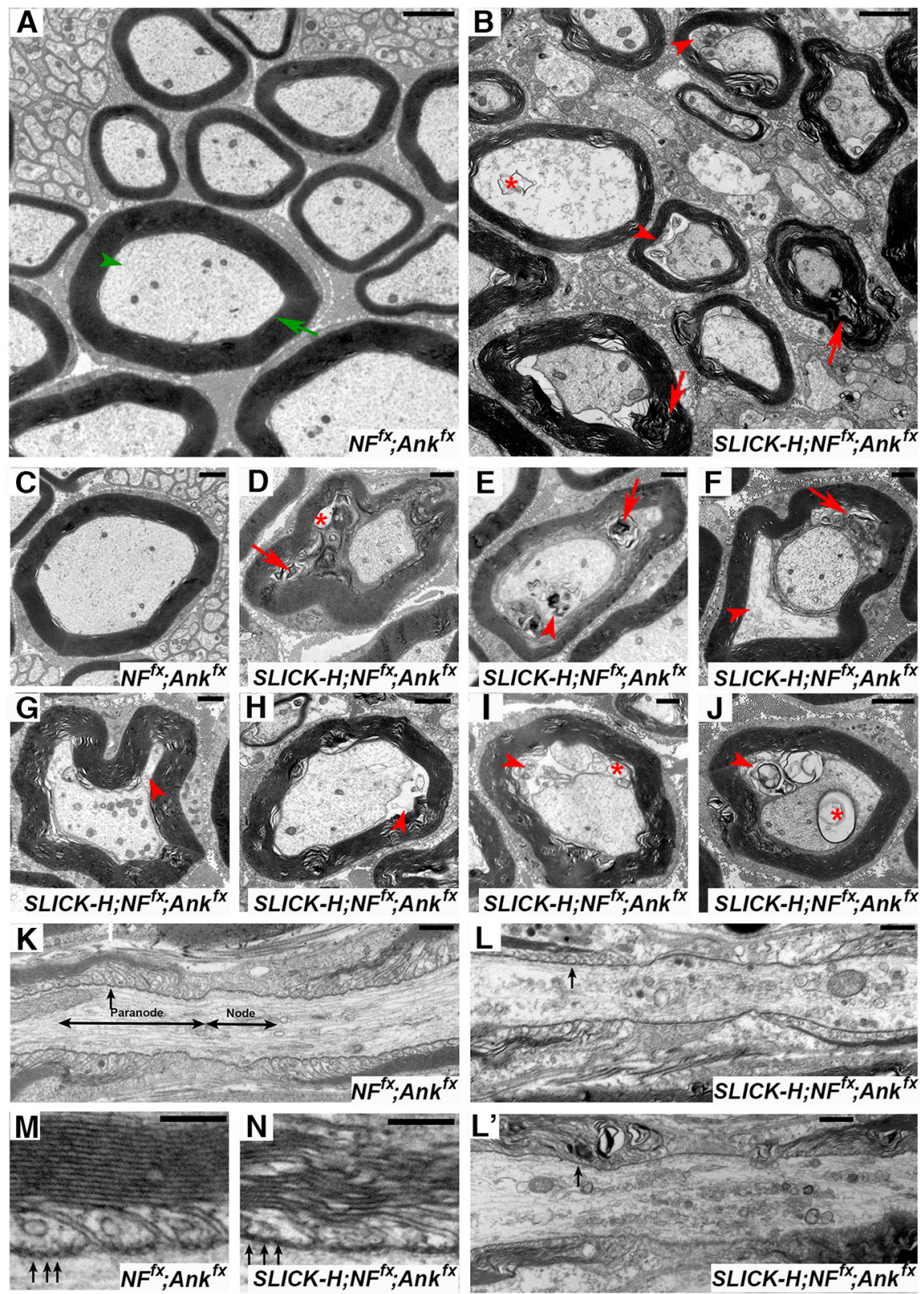

Figure 7. Destabilization of the nodal protein complex leads to sciatic nerve axonal abnormalities. $\boldsymbol{A}-\boldsymbol{J}$, Transmission electron microscopy (TEM) of cross sections from SNs of $N F^{f x} ; A n k^{f x}$ control $(\boldsymbol{A}, \boldsymbol{C})$ and $S L I C K-H-C r e E R ; N F^{f x} ; A n k^{f x}(\boldsymbol{B}, \boldsymbol{D}-\boldsymbol{J})$ mice 60 days after P23/24 injection. Green arrowheads point to normal axons, red arrowheads to abnormal accumulations in the periaxonal space, green arrows to compact myelin, red arrows to abnormal myelin inclusions, and red asterisks to vacuoles. $\boldsymbol{K}-\boldsymbol{N}$, TEM of longitudinal sections from SNs of $N F^{f x} ; A n k^{f x}(K, M)$ and SLICK-H-CreER;NF $F^{f x} ; A n k^{f x}\left(L-L^{\prime}, \boldsymbol{N}\right)$ mice 60 dpi focusing on the nodal and paranodal areas. Black arrows mark paranodal axo-glial septate-like junctions. Scale bar for $\boldsymbol{A}-\boldsymbol{J}=2 \mu \mathrm{m}, \boldsymbol{K}-\boldsymbol{L}^{\prime}=0.5 \mu \mathrm{m}, \boldsymbol{M}, \boldsymbol{N}=0.2 \mu \mathrm{m}$.

Similar to what was observed in SN cross-sections, $\sim 1$ in 3 axons from dual ablated cKO SCs showed clear signs of axonal pathology (Fig. 8B, D-J), which was not observed in control SCs (Fig. 8A, C). As in SN, a significant number of mutant axons in the SCs appeared to have shrunk away from the ensheathing myelin, leaving gaps in periaxonal spaces filled in by vacuoles, organelle accumulations, or uncompacted myelin (Fig. 8B, $D-J$ ). These areas do not represent paranodal regions, which typically show myelin loops still attached to the axons. Preserved nodal and paranodal domains were present in both con- trols and the dual cKO in SC (Fig. $8 K, L^{\prime}$ ). As in $S N$, accumulations of debris were found to be more dense and frequent in SLICK-H;N $F^{f x ;} A n k^{f x}$ than in $N F^{f x ;} A n k^{f x}$ agematched controls. At high magnification of longitudinal sections in SCs, stereotypical electron-dense septa were found between the paranodal loops and the axolemma in both control and mutant animals (Fig. 8M, N). These data suggest that while the structure of myelin may unravel as axonal shrinkage occurs in SC, it is not accompanied by widespread demyelination in the double cKOs. Overall, the ultrastructural analyses demonstrate that simultane- 

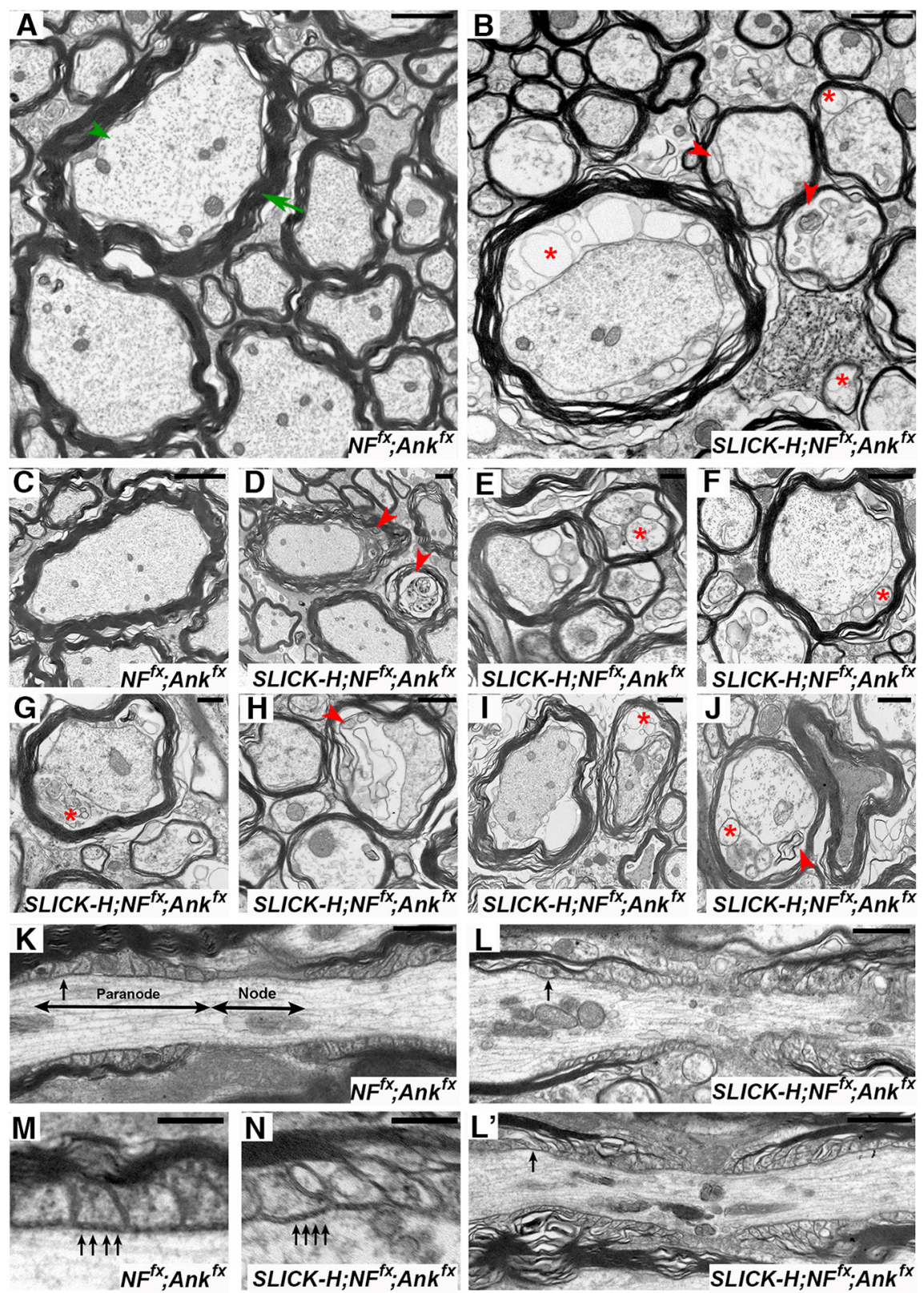

Figure 8. Destabilization of nodes leads to axonopathy in adult CNS myelinated axons. $\boldsymbol{A}-\boldsymbol{J}$, TEM of cross sections from SCs of $N F^{f x} ; A n k^{f x}$ control $(\boldsymbol{A}, \boldsymbol{C})$ and SLICK-H-CreER;NF ${ }^{f x} ; A n k^{f x}(\boldsymbol{B}, \boldsymbol{D}-\boldsymbol{J})$ mice 60 days after P23/24 injection. Green arrowheads point to normal axons, greens arrows to compact myelin, red arrowheads to abnormal accumulations in the periaxonal space, and red asterisks to vacuoles. $\boldsymbol{K}-\boldsymbol{N}$, TEM of longitudinal sections from SCs of $N F^{f x} ; A n k^{f x}(\boldsymbol{K}, \boldsymbol{M})$ and $S L I C K-H-C r e E R ; N F^{f x} ; A n k^{f x}\left(\boldsymbol{L}-\boldsymbol{L}^{\prime}, \boldsymbol{N}\right)$ mice 60 dpi focusing on the nodal and paranodal areas. Black arrows mark paranodal axo-glial septate-like junctions. Scale bar for $\boldsymbol{A}-\boldsymbol{J}=2 \mu \mathrm{m}$, $\boldsymbol{K}-\boldsymbol{L}^{\prime}=0.5 \mu \mathrm{m}, \boldsymbol{M}, \boldsymbol{N}=0.2 \mu \mathrm{m}$.

ous ablation of a cytoskeletal component together with a cell adhesion molecule at the nodes has dramatic consequences on myelinated axons, leading to ultrastructural changes associated with axonal pathology. These observations further underscore that AnkG and NF186 work synergistically throughout life to preserve the nodal structure and ultimately to maintain proper axonal architecture for saltatory nerve conduction.

\section{Discussion}

The nodal complex after initial clustering undergoes a period of maturation followed by precise maintenance for the rest of adult life to ensure proper neuronal activity. Perturbations that may affect nodal functions below a certain threshold will dramatically alter neuronal functions. In the current study, we used spatiotemporal tools to address the mutual roles of NF186 and AnkG in the stability of the node and how combined loss of these proteins at different times points during postnatal life impacts nodal stability. Here we report that when NF186 is ablated in combination with AnkG, there is accelerated loss of both these proteins which coincides with enhanced nodal destabilization, significant reduction in 
nerve conduction, and ultimately quicker demise of myelinated axons compared to ablation of these key nodal proteins individually. Furthermore, we demonstrate that the timing at which ablation occurs determines the rate of nodal destabilization. These studies uncover that nodal stability increases over time during early postnatal development and that maintenance of the steady-state levels of nodal proteins without significant turnover is beneficial for maintaining optimal nerve conduction along myelinated axons.

\section{Nodal stability and the aging node of Ranvier}

The dual loss of AnkG/NF186 has permitted us to define the timeline and consequences of nodal degeneration in vivo at different critical points in nodal stability: maturation and early-to-late maintenance (see Fig. 9). The impact of loss of single components on nodal maintenance revealed that the nodal complex remained remarkably stable for greater than half a year after AnkG or NF186 ablation (Saifetiarova et al., 2017; Taylor et al., 2017). However, it remained unresolved as to what impact loss of these proteins would have on nodes later in adult life. Ablating NF186/AnkG after 3 months (P93) significantly delayed nodal destabilization and furthermore had a profound doubling effect on the lifespan of the mice compared to dual ablated at P23. Interestingly, these late ablated mice did not show a significant reduction in weight compared to their littermate controls, even at the final time point of 120 dpi (Fig. 1), which was seen with both P13 and P23 ablation of NF186 and AnkG. Of note, the increase in lifespan and the delay in nodal destabilization after P93 ablation did not occur because of a difference in the effectiveness of tamoxifen knockdown in older mice, as the number of nodes which showed ablation of AnkG and NF186 were equal across all timelines in both PNS and CNS (Fig. 2). Instead the difference in increased nodal stability was correlated with the increased nodal half-life of AnkG and NF186, so that the core nodal proteins are degraded from the node quickest after ablation at $\mathrm{P} 13$ but persisted longer as nodes got older as in P93 or when AnkG or NF186 were ablated individually.

Together, these findings raise the important question of what makes a node different along a myelinated axon at P13, P23, and P93 contributing to its increased stability. While early in development with increasing myelination, nodes of Ranvier are known to undergo a maturation step from $\mathrm{Na}_{v} 1.2$ to $\mathrm{Na}_{v} 1.6$ (Boiko et al., 2001; Kaplan et al., 2001), the molecular composition of the node has been thought to remain relatively stable between P23 and P93 in SN and SC. Using in vitro myelinating coculture studies, a change was shown to occur over time in the way cell adhesion proteins accumulate at the node, which contributes to the slow turnover of these proteins, but this switch in the source of nodal proteins was suggested to happen before P14 in mice (Zhang et al., 2012). Although no changes at the node have been described thus far to account for the increasing stability seen between P23 and P93, one possibility is that, as the node is maintained, perhaps more nodal proteins accumulate; however, we were unable to detect significant changes in either the level or intensities of core nodal components within this time range (data not shown).

Another plausible hypothesis for increased stability is that a difference occurs not in the nodal composition but in the compaction of these proteins at the node with time. In support of this, axonal constriction was described at the node of Ranvier and has been shown to begin before birth and to continue to increase with age until after 8 weeks and then to remain stable into adulthood in feline models (Sward et al., 1995). This nodal constriction has been proposed not only to interfere with axonal transport, limiting the diffusion of proteins from the node, but also to contribute to the age-dependent increase in nerve conduction velocity along myelinated fibers (Halter and Clark, 1993; Sward et al., 1995; Johnson et al., 2015); however, the mechanism for how axonal compaction occurs and whether it is necessary for the increase in nodal stability with age remains to be determined. In addition to understanding how the nodal complex becomes more stable with age, another important question to be addressed is why this increased stabilization evolved. Although agerelated declines in myelin have been well described in many animal models (Knox et al., 1989; Albert, 1993; Peters, 2002), the integrity of the node has been shown to remain intact once fully established, while corresponding structural changes to the paranodal region have been reported with age as changes to myelin occur (Hinman et al., 2006).

\section{Nodal components and their individual and combined roles in nodal maintenance}

Although previous studies have addressed the individual roles of the transmembrane component, NF186, or the cytoskeletal component, AnkG, in nodal stability (Desmazieres et al., 2014; Ho et al., 2014; Saifetiarova et al., 2017; Taylor et al., 2017), no other study has reported the combined ablation, allowing for the first direct comparison between the intrinsic stability of these individual proteins and their roles in long-term maintenance of the nodal complex (Fig. 9B, $D, E$ ). While after ablation of NF186 at P23, the nodal half-life of NF186 was found to be $3 \mathrm{mpi}$, when AnkG was ablated with NF186 in adolescence, the nodal half-life of NF186 was significantly reduced to $30 \mathrm{dpi}$ in both PNS and CNS. A corresponding reduction in the half-life of AnkG was also seen in the dual cKO, where AnkG was completely absent from $90 \%$ of nodes by $10 \mathrm{dpi}$ compared to the single AnkG CKO, which did not reach the same levels until after 30 dpi. Without both NF186 and AnkG, adequate levels of neither $\mathrm{Na}_{V}$ channels nor $\beta$ IV Spectrin could remain clustered at the node beyond $2 \mathrm{mpi}$ to preserve nodal function, whereas single cKO mice lived beyond $6 \mathrm{mpi}$. Overall these data provide evidence for a synergistic and interdependent role of AnkG and NF186 in the maintenance of the node, so that the presence of AnkG at the node slows the rate of NF186 loss, while likewise NF186 provides additional stability as a membrane component at the node even when AnkG is lost. However, loss of AnkG makes NF186 vulnerable, leading to its loss from the nodes. 
A

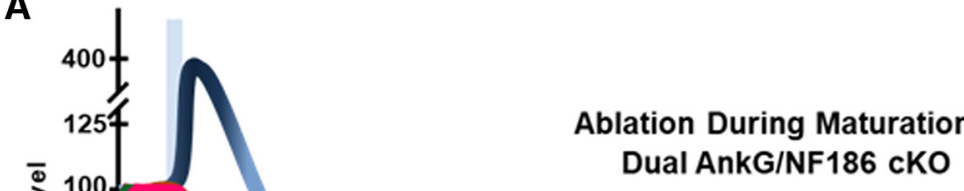

Legend:

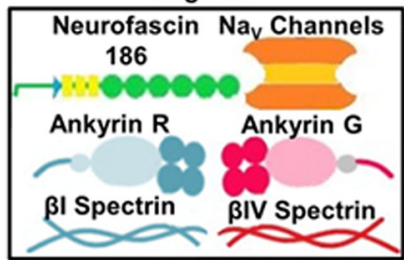

돈

B

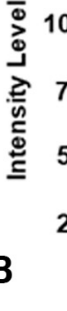

AnkR

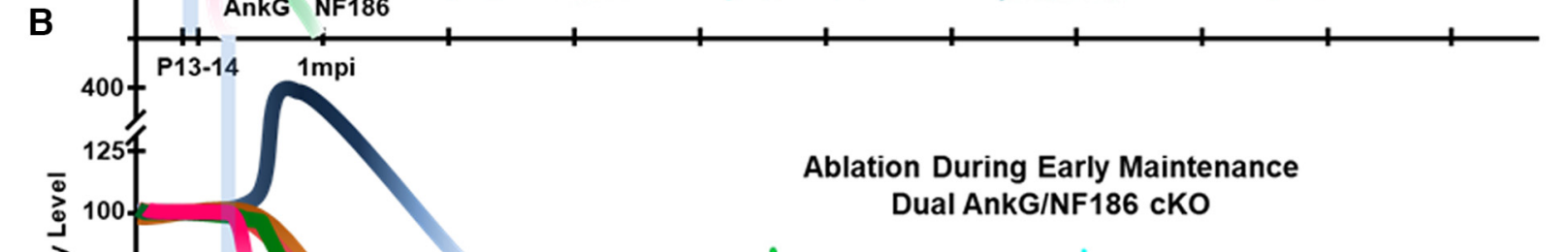

\section{c}
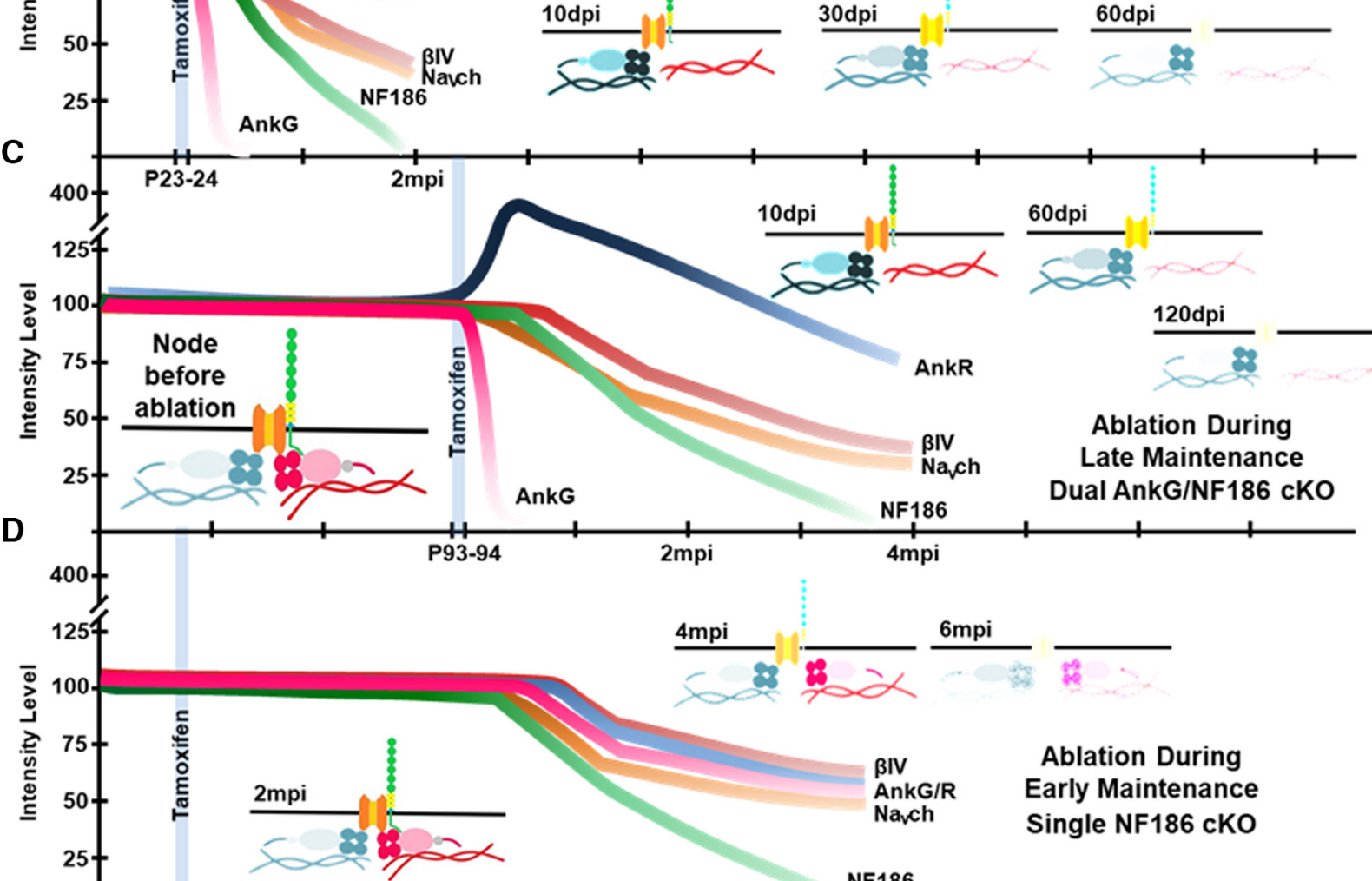

E

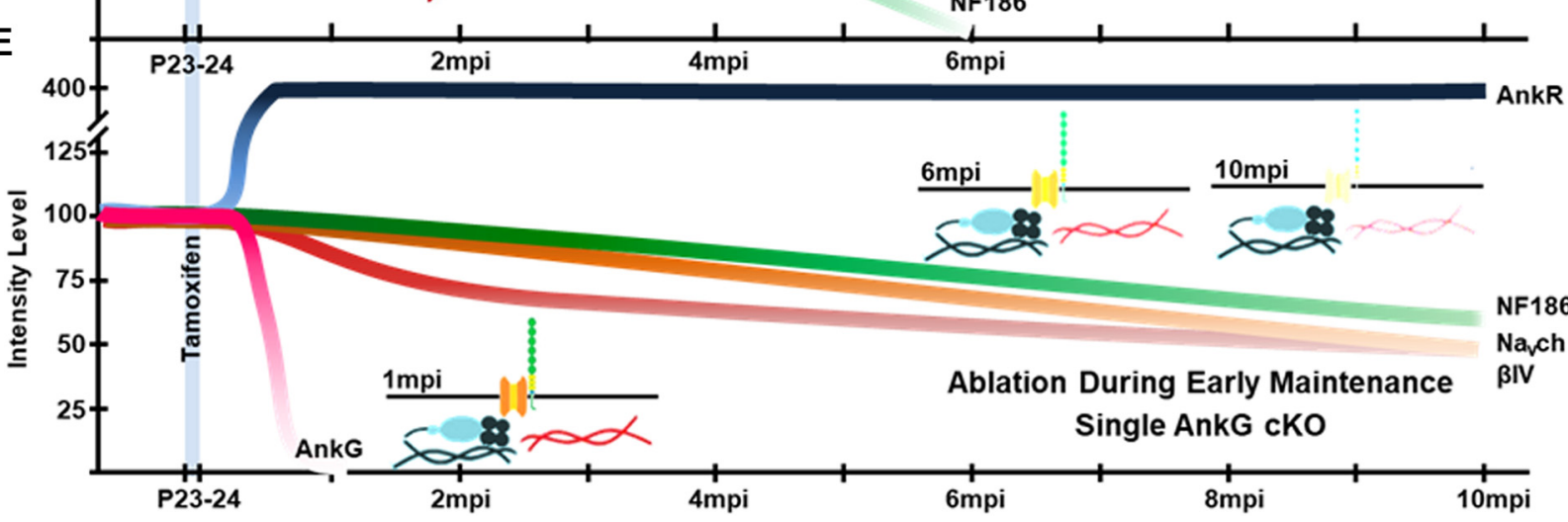

Figure 9. Schematic representation of differential nodal destabilization with age. A, P13/14 ablation of AnkG and NF186 during nodal 
continued

maturation results in a rapid nodal deterioration. By just 5 dpi, AnkG (pink line) is reduced to below $50 \%$, which leads to a dramatic increase in AnkR (blue line). By $10 \mathrm{dpi}$, AnkG is completely absent from the node, and $\beta$ IV Spectrin (red line) is being replaced by the AnkR/ $\beta$ I Spectrin complex. As NF186 (green line) levels significantly fall, corresponding reductions are seen in NaV channels (orange line) followed by $\beta$ IV Spectrin and AnkR. Mice die $\sim 1 \mathrm{mpi}$. B, P23/24 ablation of AnkG and NF186 during early nodal maintenance results in a significantly enhanced timeline of nodal destabilization compared to single cKOs. As with P13/14 ablation, AnkG is completely absent from the node by $10 \mathrm{dpi}$, and the AnkR/ $\beta \mathrm{I}$ Spectrin complex has moved in. However, the half-life of NF186 is increased to $1 \mathrm{mpi}$ with $\mathrm{P} 23 / 24$ dual ablation, and corresponding reductions in $\mathrm{Na}_{V}$ channels, $\beta$ IV Spectrin and AnkR reach a peak at $2 \mathrm{mpi}$, at which point these mice die. C, P93/94 ablation of AnkG and NF186 during late nodal maintenance results in delayed nodal deterioration compared to dual ablation at earlier time points. Although AnkG is still completely absent from the node by 10 dpi and AnkR has begun to move in, the half-life of NF186 is increased to $2 \mathrm{mpi}$ with dual ablation at 3 months of age. Reductions in Na channels, $\beta$ IV Spectrin, and AnkR continue until $4 \mathrm{mpi}$, when mice die. $\boldsymbol{D}, \mathrm{P} 23 / 24$ single ablation of NF186 during early nodal maintenance results in a gradual reduction of NF186 that is not completely lost until 6 mpi. As NF186 levels significantly decline, corresponding reductions are seen in $\mathrm{Na}_{\mathrm{V}}$ channels, AnkG, AnkR, and $\beta \mathrm{IV}$ Spectrin. Mice die at $6 \mathrm{mpi}$. E, P23/24 single ablation of AnkG during early nodal maintenance results in a rapid loss of AnkG and increase of AnkR over the first 1 mpi. However, nodal destabilization occurs very slowly, with $\beta \mathrm{IV}$ Spectrin, $\mathrm{Na}_{\mathrm{V}}$ channels, and NF186 falling below $50 \%$ at 10 mpi, at which point these mice die.

Furthermore, when ablated at P23, the dual NF186/ AnkG cKO showed faster kinetics of nodal complex destabilization than the previously studied double NF186/ NF155 cKO that had disruption of both the nodes and the flanking paranodal region (Taylor et al., 2017). In these studies, paranodes were shown to contribute to, but not to be required for, the long-term maintenance of the nodal complex; as $\mathrm{Na}_{v}$ channels were shown to be preserved at the node throughout the lifespan in P23 ablated single NF155 cKO mice, as well as in other well-characterized paranodal mutant mice (Bhat et al., 2001; Boyle et al., 2001; Pillai et al., 2009; Taylor et al., 2017). The contribution of paranodes to nodal maintenance raises the possibility that the differences in nodal stability seen with age could be due to the presence of intact paranodal domains and their maturation over time. Furthermore, loss of AnkG/NF186 at any time point did not seem to significantly affect the flanking paranodal regions, as observed by immunostaining of paranodal markers (Figs. 2-5) and the ultrastructural analyses of paranodal loops (Figs. 7 and 8). Thus with NF186 and AnkG combined ablation, nodes deteriorate much faster even in the presence of intact paranodes, suggesting intrinsic nodal destabilization. Overall, these current data further support that the intrinsic stability of nodal AnkG with NF186 is both sufficient and essential to the lifelong maintenance of the node.

\section{Timing of nodal destabilization and its impact on myelinated axons}

The sequence of nodal destabilization and the downstream consequences are of particular relevance to many human neuropathies and myelinating disorders including multiple sclerosis (MS), where nodes and paranodes have been shown to undergo progressive disorganization that correlates with disease severity (Craner et al., 2004; Coman et al., 2006; Lonigro and Devaux, 2009; Desmazières et al., 2012; Devaux et al., 2012). While the primary target of MS is the myelin sheath, axonal damage is reported to be a chief factor in the disability of the disease, leading to reduced quality of life (Haines et al., 2011; Luessi et al., 2012). Yet, the underlying cause and timeline of axonal pathology in demyelinating neuropathologies remains an area of active investigation. In our studies, no matter the timing of ablation, all mice that lost AnkG/NF186 showed a similar pattern of nodal destabilization in both PNS and CNS: (1) AnkG was undetectable at the majority of nodes by 10 dpi and AnkR levels increased; (2) NF186 levels were reduced over a span of time which correlated with the lifespan of the mice; and (3) $\mathrm{Na}_{V}$ channels, $\beta I V$ Spectrin, and AnkR diffused from the node as levels of NF186 dropped (Figs. 3-5).

As $\mathrm{Na}_{V}$ channel levels were significantly reduced at the node, in vivo electrophysiological recordings from the $\mathrm{SN}$ showed reduced conduction velocity and amplitude. The first appearance of these decreases in nerve conduction were highly associated with timing of ablation, as loss of NCV was significant early as 10 dpi after early P13/14 ablation but did not appear until after $60 \mathrm{dpi}$ in the late ablation group (Fig. 6). This reduction in nerve conduction was ultimately reflected by paralysis of the mice. As was previously reported after single ablation of AnkG and NF186, in all timelines dual ablation of AnkG/NF186 lead to ultrastructural changes in myelinated axons of both SC and SN consistent with axonal pathology. At a final time point when both NF186 and AnkG were fully lost from the nodes, ultrastructural analysis revealed axonal pathology and signs of abnormal myelin remodeling including infolding loops and budding, which often follows axonal atrophy (Bilbao and Schmidt, 2014); however, no significant level of demyelination was observed (Figs. 7 and 8). Thus, while delaying the ablation of NF186/AnkG slowed the degeneration of the nodal complex, at the final time point all the mice displayed similar motor dysfunction that correlated with changes in axonal structure.

Overall, our data support the idea that nodes of Ranvier continue to mature and achieve greater stability with age, and disrupting nodal integrity by perturbation of one or more proteins either during early maturation or during long-term maintenance leads to a sequential disorganization of the nodal proteins. Our data further highlight that nodal proteins undergo a very slow turnover as nodal compaction increases, which is designed to ensure optimal nerve conduction and axonal health for proper neuronal functions. 
Table 1. Statistical summary

\begin{tabular}{|c|c|c|c|c|c|c|}
\hline Item & Figure & Data structure & Type of test & Description & Comparison & Power \\
\hline \multirow[t]{7}{*}{$a$} & $1 F$ & Normal distribution & $\begin{array}{l}\text { Mantel-Cox log rank test; Bonferroni } \\
\text { post hoc analysis; } K=6\end{array}$ & Survival postinjection & & \\
\hline & & & & & Control vs. P13 ablation DKO & $\begin{aligned} & \chi^{2}=51.18 \\
& p<0.0001\end{aligned}$ \\
\hline & & & & & P13 ablation DKO vs. P23 ablation DKO & $\begin{aligned} \chi^{2} & =25.28 \\
p & <0.0001\end{aligned}$ \\
\hline & & & & & P13 ablation DKO vs. P93 ablation DKO & $\begin{aligned} \chi^{2} & =17.72 \\
p & <0.0001\end{aligned}$ \\
\hline & & & & & Control vs. P23 ablation DKO & $\begin{aligned} x 2 & =31.28 \\
p & <0.0001\end{aligned}$ \\
\hline & & & & & P23 ablation vs. P93 ablation & $\begin{aligned} \chi^{2} & =18.68 \\
p & <0.0001\end{aligned}$ \\
\hline & & & & & Control vs. P93 ablation & $\begin{aligned} \chi^{2} & =8.0 \\
p & =0.0047\end{aligned}$ \\
\hline \multirow[t]{7}{*}{ b } & $1 G$ & Normal distribution & $\begin{array}{l}\text { Two-way ANOVA; Tukey post } \\
\text { hoc analysis }\end{array}$ & $\begin{array}{l}\text { P13 ablation: body } \\
\text { weight }\end{array}$ & & \\
\hline & & & & & Effect of genotype & $p<0.0001$ \\
\hline & & & & & Effect of timing postinjection & $p<0.0001$ \\
\hline & & & & & Genotype $\times$ timing interaction & $p=0.4746$ \\
\hline & & & & & Control 10 dpi vs. DKO $10 \mathrm{dpi}$ & $p=0.1806$ \\
\hline & & & & & Control 20 dpi vs. DKO 20 dpi & $p=0.0038$ \\
\hline & & & & & Control 30 dpi vs. DKO $30 \mathrm{dpi}$ & $p=0.0023$ \\
\hline \multirow[t]{7}{*}{ c } & $1 H$ & Normal distribution & $\begin{array}{l}\text { Two-way ANOVA; Tukey post } \\
\text { hoc analysis }\end{array}$ & $\begin{array}{l}\text { P23 ablation: body } \\
\text { weight }\end{array}$ & & \\
\hline & & & & & Effect of genotype & $p<0.0001$ \\
\hline & & & & & Effect of timing postinjection & $p=0.0457$ \\
\hline & & & & & Genotype $\times$ timing interaction & $p=0.0002$ \\
\hline & & & & & Control 10 dpi vs. DKO $10 \mathrm{dpi}$ & $p=0.9953$ \\
\hline & & & & & Control 20 dpi vs. DKO 20 dpi & $p=1943$ \\
\hline & & & & & Control 60 dpi vs. DKO $60 \mathrm{dpi}$ & $p<0.0001$ \\
\hline \multirow[t]{7}{*}{ d } & $1 /$ & Normal distribution & $\begin{array}{l}\text { Two-way ANOVA; Tukey post } \\
\text { hoc analysis }\end{array}$ & $\begin{array}{l}\text { P93 ablation: body } \\
\text { weight }\end{array}$ & & \\
\hline & & & & & Effect of genotype & $p=1410$ \\
\hline & & & & & Effect of timing postinjection & $p<0.0001$ \\
\hline & & & & & Genotype $\times$ timing interaction & $p=0.2562$ \\
\hline & & & & & Control 10 dpi vs. DKO $10 \mathrm{dpi}$ & $p>0.9999$ \\
\hline & & & & & Control 20 dpi vs. DKO 20 dpi & $p=0.9996$ \\
\hline & & & & & Control 1200 dpi vs. DKO 120 dpi & $p=0.3155$ \\
\hline \multirow[t]{16}{*}{ e } & $2 J$, AnkG & Normal distribution & $\begin{array}{l}\text { Two-way ANOVA; Tukey post } \\
\text { hoc analysis }\end{array}$ & $\begin{array}{l}\text { SN P13 ablation: AnkG } \\
\text { nodal count }\end{array}$ & & \\
\hline & & & & & Effect of genotype & $p<0.0001$ \\
\hline & & & & & Effect of timing postinjection & $p<0.0001$ \\
\hline & & & & & Genotype $\times$ timing interaction & $p<0.0001$ \\
\hline & & & & & Control 10 dpi vs. Ank cKO $10 \mathrm{dpi}$ & $p=0.0694$ \\
\hline & & & & & Control 20 dpi vs. Ank cKO 20 dpi & $p<0.0001$ \\
\hline & & & & & Control 30 dpi vs. Ank cKO 30 dpi & $p<0.0001$ \\
\hline & & & & & Control 10 dpi vs. DKO $10 \mathrm{dpi}$ & $p<0.0001$ \\
\hline & & & & & Control 20 dpi vs. DKO 20 dpi & $p<0.0001$ \\
\hline & & & & & Control 30 dpi vs. DKO 30 dpi & $p<0.0001$ \\
\hline & & & & & Ank cKO 10 dpi vs. $20 \mathrm{dpi}$ & $p=0.0010$ \\
\hline & & & & & Ank cKO 10 dpi vs. $30 \mathrm{dpi}$ & $p<0.0001$ \\
\hline & & & & & Ank cKO 20 dpi vs. $30 \mathrm{dpi}$ & $p<0.0001$ \\
\hline & & & & & DKO 10 dpi vs. 20 dpi & $p>0.9999$ \\
\hline & & & & & DKO 10 dpi vs. 30 dpi & $p=0.9997$ \\
\hline & & & & & DKO 20 dpi vs. 30 dpi & $p>0.9999$ \\
\hline \multirow[t]{11}{*}{$f$} & 2J, NF186 & Normal distribution & $\begin{array}{l}\text { Two-way ANOVA; Tukey post } \\
\text { hoc analysis }\end{array}$ & $\begin{array}{l}\text { SN P13 ablation: NF186 } \\
\text { nodal count }\end{array}$ & & \\
\hline & & & & & Effect of genotype & $p<0.0001$ \\
\hline & & & & & Effect of timing postinjection & $p<0.0001$ \\
\hline & & & & & Genotype $\times$ timing interaction & $p<0.0001$ \\
\hline & & & & & Control 30 dpi vs. Ank cKO 30 dpi & $p>0.9999$ \\
\hline & & & & & Control $10 \mathrm{dpi}$ vs. DKO $10 \mathrm{dpi}$ & $p=0.9984$ \\
\hline & & & & & Control 20 dpi vs. DKO $20 \mathrm{dpi}$ & $p=0.0015$ \\
\hline & & & & & Control 30 dpi vs. DKO 30 dpi & $p<0.0001$ \\
\hline & & & & & DKO 10 dpi vs. 20 dpi & $p=0.0042$ \\
\hline & & & & & DKO 10 dpi vs. 30 dpi & $p<0.0001$ \\
\hline & & & & & DKO 20 dpi vs. $30 \mathrm{dpi}$ & $p<0.0001$ \\
\hline \multirow[t]{10}{*}{ g } & $2 J^{\prime}$, AnkG & Normal distribution & $\begin{array}{l}\text { Two-way ANOVA; Tukey post } \\
\text { hoc analysis }\end{array}$ & $\begin{array}{l}\text { SC P13 ablation: AnkG } \\
\text { nodal count }\end{array}$ & & \\
\hline & & & & & Effect of genotype & $p<0.0001$ \\
\hline & & & & & Effect of timing postinjection & $p<0.0001$ \\
\hline & & & & & Genotype $\times$ timing interaction & $p<0.0001$ \\
\hline & & & & & Control 10 dpi vs. Ank cKO 10 dpi & $p<0.0001$ \\
\hline & & & & & Control 20 dpi vs. Ank cKO 20 dpi & $p<0.0001$ \\
\hline & & & & & Control 30 dpi vs. Ank cKO 30 dpi & $p<0.0001$ \\
\hline & & & & & Control 10 dpi vs. DKO $10 \mathrm{dpi}$ & $p<0.0001$ \\
\hline & & & & & Control 20 dpi vs. DKO 20 dpi & $p<0.0001$ \\
\hline & & & & ed) & & \\
\hline
\end{tabular}


Table 1. Continued

\begin{tabular}{|c|c|c|c|c|}
\hline Item & Figure & Data structure & Type of test & Description \\
\hline
\end{tabular}
nodal count

N P23 ablation: AnkG nodal count

$$
\text { hoc analysis }
$$

Two-way ANOVA; Tukey post hoc analysis
Two-way ANOVA; Tukey post hoc analysis
SN P23 ablation: NF186 nodal count

SC P23 ablation: AnkG nodal count

SC P23 ablation: NF186 nodal count

$\begin{array}{ll}\text { Comparison } & \text { Power } \\ \text { Control } 30 \text { dpi vs. DKO } 30 \text { dpi } & p<0.0001 \\ \text { Ank cKO } 10 \text { dpi vs. } 20 \text { dpi } & p=0.0011 \\ \text { Ank cKO } 10 \text { dpi vs. } 30 \text { dpi } & p<0.0001 \\ \text { Ank cKO } 20 \text { dpi vs. } 30 \text { dpi } & p<0.0001 \\ \text { DKO } 10 \text { dpi vs. } 20 \text { dpi } & p=0.9973 \\ \text { DKO } 10 \text { dpi vs. } 30 \text { dpi } & p>0.9998 \\ \text { DKO } 20 \text { dpi vs. } 30 \text { dpi } & p=0.9996\end{array}$

Effect of genotype

Effect of timing postinjection

Genotype $\times$ timing interaction

Control 30 dpi vs. Ank cKO 30 dpi

Control $10 \mathrm{dpi}$ vs. DKO $10 \mathrm{dpi}$

Control 20 dpi vs. DKO $20 \mathrm{dpi}$

Control 30 dpi vs. DKO $30 \mathrm{dpi}$

DKO 10 dpi vs. $20 \mathrm{dpi}$

DKO 10 dpi vs. $30 \mathrm{dpi}$

DKO 20 dpi vs. 30 dpi

Effect of genotype

Effect of timing postinjection

Genotype $\times$ timing interaction

Control $10 \mathrm{dpi}$ vs. Ank cKO $10 \mathrm{dp}$

Control 20 dpi vs. Ank cKO 20 dp

Control 60 dpi vs. Ank cKO $60 \mathrm{dpi}$

Control $10 \mathrm{dpi}$ vs. DKO $10 \mathrm{dpi}$

Control 20 dpi vs. DKO $20 \mathrm{dp}$

Control 60 dpi vs. DKO $60 \mathrm{dpi}$

Ank cKO 10 dpi vs. 20 dpi

Ank cKO 10 dpi vs. 60 dpi

Ank cKO 20 dpi vs. 60 dpi

DKO 10 dpi vs. 20 dpi

DKO 10 dpi vs. 60 dpi

DKO 20 dpi vs. 60 dpi

$p<0.0001$

$p<0.0001$

$p<0.0001$

$p>0.9999$

$p=0.5624$

$p<0.0001$

$p<0.0001$

$p=0.0001$

$p<0.0001$

$p<0.0001$

$p<0.0001$

$p<0.0001$

$p<0.0001$

$p=0.9389$

$p<0.0001$

$p<0.0001$

$p<0.0001$

$p<0.0001$

$p<0.0001$

$p=0.0008$

$p<0.0001$

$p<0.0001$

$p>0.9999$

$p>0.9999$

$p=0.8804$

Effect of genotype

Effect of timing postinjection

Genotype $\times$ timing interaction

Control 60 dpi vs. Ank cKO $60 \mathrm{dpi}$

Control $10 \mathrm{dpi}$ vs. DKO $10 \mathrm{dpi}$

Control 20 dpi vs. DKO 20 dpi

Control 60 dpi vs. DKO $60 \mathrm{dpi}$

DKO 10 dpi vs. 20 dpi

DKO 10 dpi vs. 60 dpi

DKO 20 dpi vs. 60 dpi

$p<0.0001$

$p<0.0001$

$p<0.0001$

$p>0.9999$

$p=0.9943$

$p=0.0031$

$p<0.0001$

$p=0.0089$

$p<0.0001$

$p<0.0001$

Effect of genotype

Effect of timing postinjection

Genotype $\times$ timing interaction

Control $10 \mathrm{dpi}$ vs. Ank cKO $10 \mathrm{dpi}$

Control 20 dpi vs. Ank cKO 20 dpi

Control 60 dpi vs. Ank cKO $60 \mathrm{dpi}$

Control $10 \mathrm{dpi}$ vs. DKO $10 \mathrm{dpi}$

Control 20 dpi vs. DKO 20 dp

Control 60 dpi vs. DKO $60 \mathrm{dpi}$

Ank cKO 10 dpi vs. $20 \mathrm{dpi}$

Ank cKO 10 dpi vs. $60 \mathrm{dpi}$

Ank cKO 20 dpi vs. 60 dpi

DKO 10 dpi vs. $20 \mathrm{dpi}$

DKO 10 dpi vs. $60 \mathrm{dpi}$

DKO 20 dpi vs. 60 dpi

$p<0.0001$

$p<0.0001$

$p<0.0001$

$p<0.0001$

$p<0.0001$

$p<0.0001$

$p<0.0001$

$p<0.0001$

$p<0.0001$

$p<0.0001$

$p<0.0001$

$p<0.0001$

$p>0.9999$

$p>0.9999$

$p=0.9991$

Effect of genotype

Effect of timing postinjection

Genotype $\times$ timing interaction

Control 60 dpi vs. Ank cKO 60 dpi

Control $10 \mathrm{dpi}$ vs. DKO $10 \mathrm{dpi}$

Control 20 dpi vs. DKO $20 \mathrm{dp}$

Control 60 dpi vs. DKO $60 \mathrm{dpi}$

DKO 10 dpi vs. 20 dpi

DKO $10 \mathrm{dpi}$ vs. $60 \mathrm{dpi}$

DKO 20 dpi vs. 60 dpi $p<0.0001$

$p<0.0001$

$p<0.0001$

$p>0.9999$

$p=0.6324$

$p=0.0001$

$p<0.0001$

$p=0.0009$

$p<0.0001$

$p<0.0001$ 
Table 1. Continued

\begin{tabular}{llll}
\hline Item & Figure & Data structure & Type of test \\
\hline $\mathrm{m}$ & $2 L$, AnkG & Normal distribution & Two-way ANOVA; Tukey post
\end{tabular}
hoc analysis

n 2L, NF186 Normal distribution

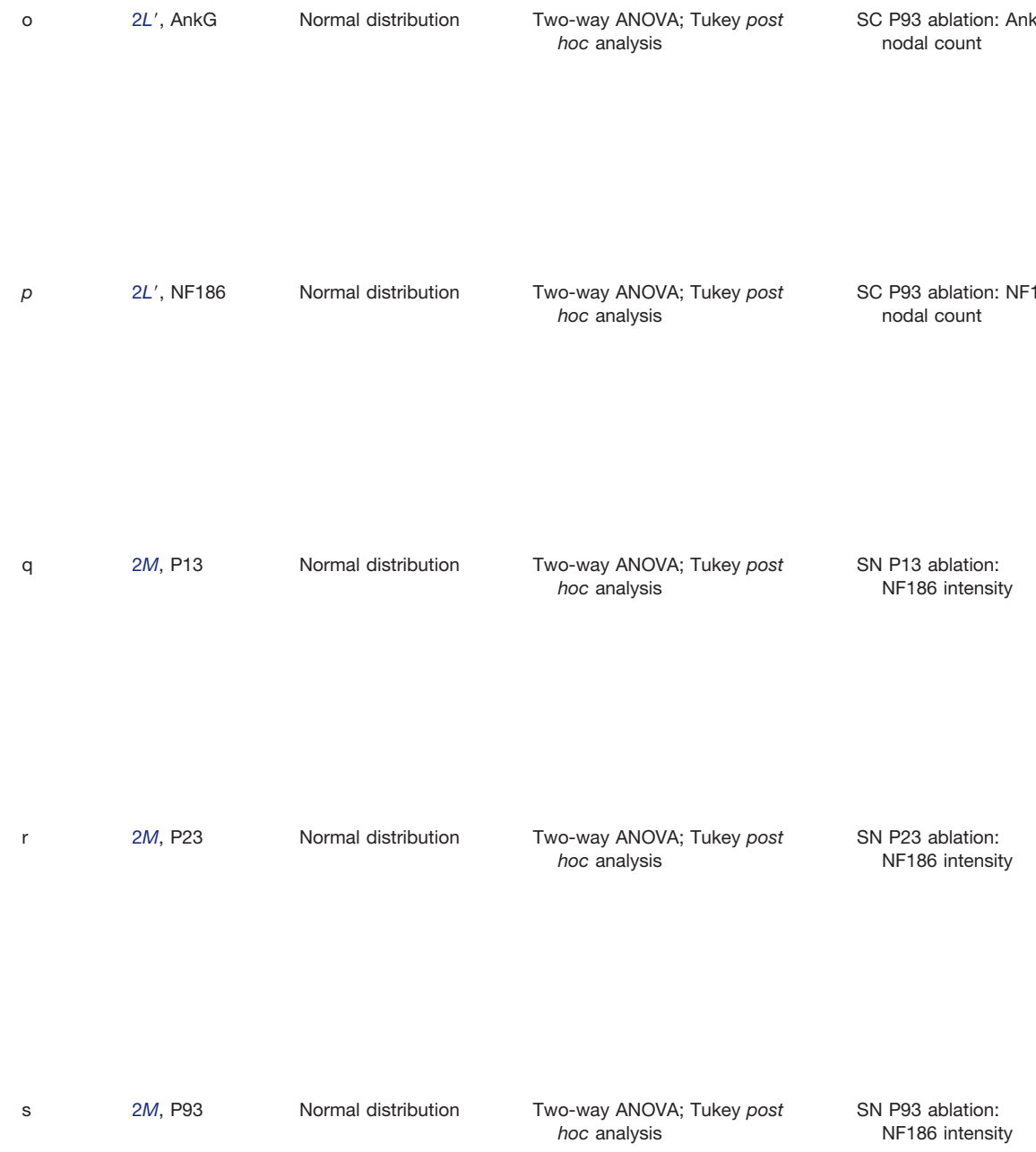

SN P93 ablation: NF186 nodal count

Description
SN P93 ablation: AnkG
nodal count

Comparison

Effect of genotype

$p<0.0001$

Effect of timing postinjection

Genotype $\times$ timing interaction

Control $10 \mathrm{dpi}$ vs. DKO $10 \mathrm{dpi}$

Control 20 dpi vs. DKO $20 \mathrm{dpi}$

Control 120 dpi vs. DKO 120 dpi

DKO 10 dpi vs. $20 \mathrm{dp}$

DKO 10 dpi vs. $120 \mathrm{dpi}$

DKO 20 dpi vs. 120 dpi

Effect of genotype

Effect of timing postinjection

Genotype $\times$ timing interaction

Control 10 dpi vs. DKO $10 \mathrm{dpi}$

Control 20 dpi vs. DKO 20 dpi

Control 120 dpi vs. DKO 120 dpi

DKO 10 dpi vs. 20 dpi

DKO 10 dpi vs. $120 \mathrm{dpi}$

DKO 20 dpi vs. 120 dpi

$p=0.9562$

$p=0.1124$

$p<0.0001$

$p<0.0001$

$p<0.0001$

$p=0.7683$

$p=0.9502$

$p=0.9925$

$p<0.0001$

$p<0.0001$

$p<0.0001$

$p=0.1372$

$p=0.0182$

$p<0.0001$

$p=0.9704$

$p<0.0001$

$p<0.0001$

Effect of genotype

Effect of timing postinjection

Genotype $\times$ timing interaction

Control $10 \mathrm{dpi}$ vs. DKO $10 \mathrm{dpi}$

Control 20 dpi vs. DKO 20 dpi

Control 120 dpi vs. DKO 120 dpi

DKO 10 dpi vs. 20 dpi

DKO 10 dpi vs. 120 dpi

DKO 20 dpi vs. 120 dpi

$p<0.0001$

$p=0.0083$

$p=0.0063$

$p<0.0001$

$p<0.0001$

$p<0.0001$

$p=0.1040$

$p=0.0010$

$p=0.2210$

Effect of genotype

Effect of timing postinjection

Genotype $\times$ timing interaction

Control $10 \mathrm{dpi}$ vs. DKO $10 \mathrm{dpi}$

Control 20 dpi vs. DKO 20 dpi

Control 120 dpi vs. DKO 120 dpi

DKO 10 dpi vs. 20 dpi

DKO 10 dpi vs. $120 \mathrm{dpi}$

DKO 20 dpi vs. $120 \mathrm{dpi}$

$p<0.0001$

$p<0.0001$

$p<0.0001$

$p=0.9167$

$p=0.4298$

$p<0.0001$

$p=0.9131$

$p<0.0001$

$p<0.0001$

Effect of genotype

$p<0.0001$

$p=0.0001$

$p=0.0001$

$p=0.4702$

$p=0.0001$

$p<0.0001$

$p=0.0125$

$p<0.0001$

$p=0.0036$

DKO 10 dpi vs. $30 \mathrm{dp}$

DKO 20 dpi vs. $30 \mathrm{dp}$

$p=0.0007$

$p=0.0308$

$p=0.0308$

$p=0.9972$

$p=0.2550$

$p=0.0029$

$p=0.5495$

$p=0.0070$

$p=0.1800$

DKO 10 dpi vs. $60 \mathrm{dpi}$

DKO 20 dpi vs. 60 dp

Effect of genotype

$p<0.0001$

$p<0.0001$

$p<0.0001$

$p>0.9999$

$p=0.2330$

$p<0.0001$

$p=0.2696$

$p<0.0001$

$p=0.0003$ 
Table 1. Continued

\begin{tabular}{|c|c|c|c|c|c|c|}
\hline Item & Figure & Data structure & Type of test & Description & Comparison & Power \\
\hline \multirow[t]{10}{*}{$\mathrm{t}$} & $2 M^{\prime}, \mathrm{P} 13$ & Normal distribution & $\begin{array}{l}\text { Two-way ANOVA; Tukey post } \\
\text { hoc analysis }\end{array}$ & $\begin{array}{l}\text { SC P13 ablation: } \\
\text { NF186 intensity }\end{array}$ & & \\
\hline & & & & & Effect of genotype & $p<0.0001$ \\
\hline & & & & & Effect of timing postinjection & $p=0.0003$ \\
\hline & & & & & Genotype $\times$ timing interaction & $p=0.0003$ \\
\hline & & & & & Control 10 dpi vs. DKO $10 \mathrm{dpi}$ & $p=0.9382$ \\
\hline & & & & & Control 20 dpi vs. DKO 20 dpi & $p=0.0971$ \\
\hline & & & & & Control 30 dpi vs. DKO $30 \mathrm{dpi}$ & $p<0.0001$ \\
\hline & & & & & DKO 10 dpi vs. $20 \mathrm{dpi}$ & $p=0.5018$ \\
\hline & & & & & DKO 10 dpi vs. 30 dpi & $p<0.0001$ \\
\hline & & & & & DKO 20 dpi vs. 30 dpi & $p=0.0009$ \\
\hline \multirow[t]{10}{*}{$\mathrm{u}$} & $2 M^{\prime}, \mathrm{P} 23$ & Normal distribution & $\begin{array}{l}\text { Two-way ANOVA; Tukey post } \\
\text { hoc analysis }\end{array}$ & $\begin{array}{l}\text { SC P23 ablation: } \\
\text { NF186 intensity }\end{array}$ & & \\
\hline & & & & & Effect of genotype & $p=0.0013$ \\
\hline & & & & & Effect of timing postinjection & $p=0.0112$ \\
\hline & & & & & Genotype $\times$ timing interaction & $p=0.0113$ \\
\hline & & & & & Control $10 \mathrm{dpi}$ vs. DKO $10 \mathrm{dpi}$ & $p>0.9999$ \\
\hline & & & & & Control 20 dpi vs. DKO 20 dpi & $p=0.5115$ \\
\hline & & & & & Control 60 dpi vs. DKO 60 dpi & $p=0.0010$ \\
\hline & & & & & DKO 10 dpi vs. $20 \mathrm{dpi}$ & $p=0.6657$ \\
\hline & & & & & DKO 10 dpi vs. $60 \mathrm{dpi}$ & $p=0.0028$ \\
\hline & & & & & DKO 20 dpi vs. 60 dpi & $p=0.0329$ \\
\hline \multirow[t]{10}{*}{ v } & $2 M^{\prime}, \mathrm{P} 93$ & Normal distribution & $\begin{array}{l}\text { Two-way ANOVA; Tukey post } \\
\text { hoc analysis }\end{array}$ & $\begin{array}{l}\text { SC P93 ablation: } \\
\text { NF186 intensity }\end{array}$ & & \\
\hline & & & & & Effect of genotype & $p=0.0007$ \\
\hline & & & & & Effect of timing postinjection & $p<0.0001$ \\
\hline & & & & & Genotype $\times$ timing interaction & $p<0.0001$ \\
\hline & & & & & Control 10 dpi vs. DKO $10 \mathrm{dpi}$ & $p>0.9999$ \\
\hline & & & & & Control 20 dpi vs. DKO 20 dpi & $p=0.9996$ \\
\hline & & & & & Control 120 dpi vs. DKO 120 dpi & $p<0.0001$ \\
\hline & & & & & DKO 10 dpi vs. 20 dpi & $p=0.9978$ \\
\hline & & & & & DKO 10 dpi vs. $120 \mathrm{dpi}$ & $p<0.0001$ \\
\hline & & & & & DKO 20 dpi vs. 120 dpi & $p<0.0001$ \\
\hline \multirow[t]{5}{*}{ w } & $2 Q$ & Normal distribution & $\begin{array}{l}\text { Unpaired, two- } \\
\text { tailed } t \text { test }\end{array}$ & $\begin{array}{l}\text { SN P13 ablation: relative } \\
\text { protein level }\end{array}$ & & \\
\hline & & & & & AnkG level: control vs. Ank cKO & $p=0.0002$ \\
\hline & & & & & AnkG level: control vs. DKO & $p=0.006$ \\
\hline & & & & & NF186 level: control vs. Ank cKO & $p=0.9415$ \\
\hline & & & & & NF186 level: control vs. DKO & $p=0.0062$ \\
\hline \multirow[t]{5}{*}{$x$} & $2 Q^{\prime}$ & Normal distribution & $\begin{array}{l}\text { Unpaired, two- } \\
\text { tailed } t \text { test }\end{array}$ & $\begin{array}{l}\text { SC P13 ablation: relative } \\
\text { protein level }\end{array}$ & & \\
\hline & & & & & AnkG level: control vs. Ank cKO & $p=0.0079$ \\
\hline & & & & & AnkG level: control vs. DKO & $p=0.0013$ \\
\hline & & & & & NF186 level: control vs. Ank cKO & $p=0.355$ \\
\hline & & & & & NF186 level: control vs. DKO & $p=0.0003$ \\
\hline \multirow[t]{5}{*}{ y } & $2 R$ & Normal distribution & $\begin{array}{l}\text { Unpaired, two- } \\
\text { tailed } t \text { test }\end{array}$ & $\begin{array}{l}\text { SN P23 ablation: relative } \\
\text { protein level }\end{array}$ & & \\
\hline & & & & & AnkG level: control vs. Ank cKO & $p=0.0404$ \\
\hline & & & & & AnkG level: control vs. DKO & $p=0.0046$ \\
\hline & & & & & NF186 level: control vs. Ank cKO & $p=0.3541$ \\
\hline & & & & & NF186 level: control vs. DKO & $p=0.0249$ \\
\hline \multirow[t]{5}{*}{ z } & $2 R^{\prime}$ & Normal distribution & $\begin{array}{l}\text { Unpaired, two- } \\
\text { tailed } t \text { test }\end{array}$ & $\begin{array}{l}\text { SC P23 ablation: relative } \\
\text { protein level }\end{array}$ & & \\
\hline & & & & & AnkG level: control vs. Ank cKO & $p=0.0036$ \\
\hline & & & & & AnkG level: control vs. DKO & $p=0.0016$ \\
\hline & & & & & NF186 level: control vs. Ank cKO & $p=0.7327$ \\
\hline & & & & & NF186 level: control vs. DKO & $p=0.0066$ \\
\hline \multirow[t]{3}{*}{ aa } & $2 S$ & Normal distribution & $\begin{array}{l}\text { Unpaired, two- } \\
\text { tailed } t \text { test }\end{array}$ & $\begin{array}{l}\text { SN P93 ablation: relative } \\
\text { protein level }\end{array}$ & & \\
\hline & & & & & AnkG level: control vs. DKO & $p=0.0043$ \\
\hline & & & & & NF186 level: control vs. DKO & $p<0.0001$ \\
\hline \multirow[t]{3}{*}{$a b$} & $2 S^{\prime}$ & Normal distribution & $\begin{array}{l}\text { Unpaired, two- } \\
\text { tailed } t \text { test }\end{array}$ & $\begin{array}{l}\text { SC P93 ablation: relative } \\
\text { protein level }\end{array}$ & & \\
\hline & & & & & AnkG level: control vs. DKO & $p=0.0009$ \\
\hline & & & & & NF186 level: control vs. DKO & $p=0.0002$ \\
\hline \multirow[t]{11}{*}{ ac } & $3 S, \mathrm{P} 13$ & Normal distribution & $\begin{array}{l}\text { Two-way ANOVA; Tukey post } \\
\text { hoc analysis }\end{array}$ & $\begin{array}{l}\text { SN P13 ablation: } \\
\text { NaV intensity }\end{array}$ & & \\
\hline & & & & & Effect of genotype & $p<0.0001$ \\
\hline & & & & & Effect of timing postinjection & $p<0.0001$ \\
\hline & & & & & Genotype $\times$ timing interaction & $p<0.0001$ \\
\hline & & & & & Control 10 dpi vs. DKO $10 \mathrm{dpi}$ & $p=0.9992$ \\
\hline & & & & & Control 20 dpi vs. DKO $20 \mathrm{dpi}$ & $p<0.0001$ \\
\hline & & & & & Control 30 dpi vs. DKO $30 \mathrm{dpi}$ & $p<0.0001$ \\
\hline & & & & & DKO 10 dpi vs. 20 dpi & $p<0.0001$ \\
\hline & & & & & DKO 10 dpi vs. $30 \mathrm{dpi}$ & $p<0.0001$ \\
\hline & & & & & DKO 20 dpi vs. 30 dpi & $p<0.0001$ \\
\hline & & & (Co & & & \\
\hline
\end{tabular}


Table 1. Continued

\begin{tabular}{lllll}
\hline Item & Figure & Data structure & Type of test & Description \\
\hline ad & 3S, P23 & Normal distribution & $\begin{array}{c}\text { Two-way ANOVA; Tukey post } \\
\text { hoc analysis }\end{array}$ & $\begin{array}{r}\text { SN P23 ablation: } \\
\text { NaV intensity }\end{array}$
\end{tabular}

Two-way ANOVA; Tukey post hoc analysis

SN P93 ablation: $\mathrm{NaV}$ intensity

Comparison

Power
SC P13 ablation:

$\mathrm{NaV}$ intensity

C P23 ablation: $\mathrm{NaV}$ intensity

SC- NaV: relative protein level

SN P13 ablation: BIV intensity
SN P23 ablation: BIV intensity
Effect of genotype

Effect of timing postinjection

Genotype $\times$ timing interaction

Control 10 dpi vs. DKO $10 \mathrm{dpi}$ Control 20 dpi vs. DKO 20 dpi

Control 60 dpi vs. DKO 60 dpi DKO 10 dpi vs. $20 \mathrm{dpi}$

DKO 10 dpi vs. 60 dpi

DKO 20 dpi vs. 60 dpi

Effect of genotype

Effect of timing postinjection

Genotype $\times$ timing interaction Control 10 dpi vs. DKO 10 dpi

Control 20 dpi vs. DKO 20 dpi

Control 120 dpi vs. DKO 120 dpi DKO 10 dpi vs. 20 dpi

DKO 10 dpi vs. 120 dpi

DKO 20 dpi vs. 120 dpi

Effect of genotype

Effect of timing postinjection Genotype $\times$ timing interaction Control $10 \mathrm{dpi}$ vs. DKO $10 \mathrm{dpi}$ Control 20 dpi vs. DKO 20 dpi Control 30 dpi vs. DKO $30 \mathrm{dpi}$ DKO 10 dpi vs. 20 dpi DKO 10 dpi vs. $30 \mathrm{dpi}$ DKO 20 dpi vs. 30 dp

Effect of genotype Effect of timing postinjection Genotype $\times$ timing interaction Control 10 dpi vs. DKO 10 dpi Control 20 dpi vs. DKO 20 dpi Control 60 dpi vs. DKO 60 dpi DKO 10 dpi vs. 20 dpi DKO 10 dpi vs. $60 \mathrm{dp}$ DKO 20 dpi vs. $60 \mathrm{dp}$

Effect of genotype

Effect of timing postinjection Genotype $\times$ timing interaction Control 10 dpi vs. DKO 10 dpi Control 20 dpi vs. DKO 20 dpi Control 120 dpi vs. DKO 120 dpi DKO 10 dpi vs. $20 \mathrm{dpi}$ DKO 10 dpi vs. $120 \mathrm{dpi}$ DKO 20 dpi vs. 120 dpi

Control vs. P13 ablation DKO Control vs. P23 ablation DKO Control vs. P93 ablation

$p=0.927$

$p=0.98$

Effect of genotype

Effect of timing postinjection

Genotype $\times$ timing interaction Control 10 dpi vs. DKO $10 \mathrm{dpi}$ Control 20 dpi vs. DKO 20 dpi Control 30 dpi vs. DKO 30 dpi DKO 10 dpi vs. $20 \mathrm{dpi}$ DKO 10 dpi vs. $30 \mathrm{dpi}$ DKO 20 dpi vs. 30 dpi

$p<0.0001$
$p=0.0002$
$p=0.0002$
$p=0.9996$
$p=0.0003$
$p<0.0001$
$p=0.0011$
$p<0.0001$
$p=0.93009$
$p<0.0001$
$p=0.0027$
$p=0.0027$
$p=0.9996$
$p=0.0058$
$p=0.0012$
$p=0.0032$
$p=0.0004$
$p=0.6551$
$p<0.0001$
$p=0.3498$
$p=0.3510$
$p=0.0085$
$p=0.0018$
$p=0.0003$
$p=0.9713$
$p=0.2965$
$p=0.7138$

$p<0.0001$

$p=0.0451$

$p=0.0452$

$p=0.4863$

$p=0.0089$

$p=0.0004$

$p=0.2164$

$p=0.0152$

$p=0.8617$

$p=0.0015$

$p=0.0108$

$p=0.0107$

$p=0.9987$

$p=0.7937$

$p=0.0025$

$p=0.9066$

$p=0.0026$

$p=0.0259$

$p<0.0001$

$p=0.0169$

$p=0.0170$

$p=0.1170$

$p=0.0017$

$p<0.0001$

$p=0.1209$

$p=0.0036$

$p=0.6801$

Effect of genotype

Effect of timing postinjection

Genotype $\times$ timing interaction Control 10 dpi vs. DKO $10 \mathrm{dpi}$ $p<0.0001$

$p=0.0423$

$p=0.0425$

$p=0.7035$ 
Table 1. Continued

\begin{tabular}{|c|c|c|c|c|c|c|}
\hline Item & Figure & Data structure & Type of test & Description & Comparison & Power \\
\hline & & & & & Control 20 dpi vs. DKO 20 dpi & $p=0.1771$ \\
\hline & & & & & Control 60 dpi vs. DKO 60 dpi & $p=0.0006$ \\
\hline & & & & & DKO 10 dpi vs. 20 dpi & $p=0.9089$ \\
\hline & & & & & DKO 10 dpi vs. 60 dpi & $p=0.0215$ \\
\hline & & & & & DKO 20 dpi vs. 60 dpi & $p=0.1587$ \\
\hline \multirow[t]{10}{*}{ al } & $4 S, \mathrm{P} 93$ & Normal distribution & $\begin{array}{l}\text { Two-way ANOVA; Tukey post } \\
\text { hoc analysis }\end{array}$ & $\begin{array}{l}\text { SN P93 ablation: } \\
\text { BIV intensity }\end{array}$ & & \\
\hline & & & & & Effect of genotype & $p=0.0006$ \\
\hline & & & & & Effect of timing postinjection & $p=0.0394$ \\
\hline & & & & & Genotype $\times$ timing interaction & $p=0.0394$ \\
\hline & & & & & Control 10 dpi vs. DKO $10 \mathrm{dpi}$ & $p=0.9642$ \\
\hline & & & & & Control 20 dpi vs. DKO 20 dpi & $p=0.2846$ \\
\hline & & & & & Control 120 dpi vs. DKO 120 dpi & $p=0.0040$ \\
\hline & & & & & DKO 10 dpi vs. 20 dpi & $p=0.6927$ \\
\hline & & & & & DKO 10 dpi vs. 120 dpi & $p=0.0147$ \\
\hline & & & & & DKO 20 dpi vs. 120 dpi & $p=0.1642$ \\
\hline \multirow[t]{10}{*}{ am } & $4 T, \mathrm{P} 13$ & Normal distribution & $\begin{array}{l}\text { Two-way ANOVA; Tukey post } \\
\text { hoc analysis }\end{array}$ & $\begin{array}{l}\text { SC P13 ablation: } \\
\text { BIV intensity }\end{array}$ & & \\
\hline & & & & & Effect of genotype & $p<0.0001$ \\
\hline & & & & & Effect of timing postinjection & $p=0.2569$ \\
\hline & & & & & Genotype $\times$ timing interaction & $p=0.2569$ \\
\hline & & & & & Control 10 dpi vs. DKO $10 \mathrm{dpi}$ & $p=0.0004$ \\
\hline & & & & & Control 20 dpi vs. DKO 20 dpi & $p<0.0001$ \\
\hline & & & & & Control 30 dpi vs. DKO $30 \mathrm{dpi}$ & $p<0.0001$ \\
\hline & & & & & DKO 10 dpi vs. 20 dpi & $p=0.9939$ \\
\hline & & & & & DKO 10 dpi vs. 30 dpi & $p=0.2390$ \\
\hline & & & & & DKO 20 dpi vs. 30 dpi & $p=0.5023$ \\
\hline \multirow[t]{10}{*}{ an } & $4 T, \mathrm{P} 23$ & Normal distribution & $\begin{array}{l}\text { Two-way ANOVA; Tukey post } \\
\text { hoc analysis }\end{array}$ & $\begin{array}{l}\text { SC P23 ablation: } \\
\text { BIV intensity }\end{array}$ & & \\
\hline & & & & & Effect of genotype & $p=0.0003$ \\
\hline & & & & & Effect of timing postinjection & $p=0.1459$ \\
\hline & & & & & Genotype $\times$ timing interaction & $p=0.1459$ \\
\hline & & & & & Control 10 dpi vs. DKO $10 \mathrm{dpi}$ & $p=0.8248$ \\
\hline & & & & & Control 20 dpi vs. DKO 20 dpi & $p=0.1930$ \\
\hline & & & & & Control 60 dpi vs. DKO 60 dpi & $p=0.0043$ \\
\hline & & & & & DKO 10 dpi vs. 20 dpi & $p=0.8728$ \\
\hline & & & & & DKO 10 dpi vs. 60 dpi & $p=0.0925$ \\
\hline & & & & & DKO 20 dpi vs. 60 dpi & $p=0.5341$ \\
\hline \multirow[t]{10}{*}{ ao } & $4 T$, P93 & Normal distribution & $\begin{array}{l}\text { Two-way ANOVA; Tukey post } \\
\text { hoc analysis }\end{array}$ & $\begin{array}{l}\text { SC P93 ablation: } \\
\text { BIV intensity }\end{array}$ & & \\
\hline & & & & & Effect of genotype & $p=0.0198$ \\
\hline & & & & & Effect of timing postinjection & $p=0.0050$ \\
\hline & & & & & Genotype $\times$ timing interaction & $p=0.0050$ \\
\hline & & & & & Control 10 dpi vs. DKO $10 \mathrm{dpi}$ & $p>0.9999$ \\
\hline & & & & & Control 20 dpi vs. DKO 20 dpi & $p=0.9978$ \\
\hline & & & & & Control 120 dpi vs. DKO 120 dpi & $p=0.0042$ \\
\hline & & & & & DKO 10 dpi vs. 20 dpi & $p=0.9877$ \\
\hline & & & & & DKO 10 dpi vs. 120 dpi & $p=0.0031$ \\
\hline & & & & & DKO 20 dpi vs. 120 dpi & $p=0.0019$ \\
\hline \multirow[t]{4}{*}{ ap } & $4 U$ & Normal distribution & $\begin{array}{l}\text { Unpaired, two- } \\
\text { tailed } t \text { test }\end{array}$ & $\begin{array}{l}\text { SC- BIV: relative } \\
\text { protein level }\end{array}$ & & \\
\hline & & & & & Control vs. P13 ablation DKO & $p=0.7971$ \\
\hline & & & & & Control vs. P23 ablation DKO & $p=0.9601$ \\
\hline & & & & & Control vs. P93 ablation & $p=0.8546$ \\
\hline \multirow[t]{10}{*}{ aq } & $5 S, P 13$ & Normal distribution & $\begin{array}{l}\text { Two-way ANOVA; Tukey post } \\
\text { hoc analysis }\end{array}$ & $\begin{array}{l}\text { SN P13 ablation: } \\
\text { AnkR intensity }\end{array}$ & & \\
\hline & & & & & Effect of genotype & $p<0.0001$ \\
\hline & & & & & Effect of timing postinjection & $p=0.0001$ \\
\hline & & & & & Genotype $\times$ timing interaction & $p=0.0001$ \\
\hline & & & & & Control 10 dpi vs. DKO $10 \mathrm{dpi}$ & $p=0.0005$ \\
\hline & & & & & Control 20 dpi vs. DKO 20 dpi & $p<0.0001$ \\
\hline & & & & & Control 30 dpi vs. DKO 30 dpi & $p>0.9999$ \\
\hline & & & & & DKO 10 dpi vs. 20 dpi & $p=0.0926$ \\
\hline & & & & & DKO 10 dpi vs. 30 dpi & $p=0.0009$ \\
\hline & & & & & DKO 20 dpi vs. 30 dpi & $p<0.0001$ \\
\hline \multirow[t]{11}{*}{ ar } & $5 S, \mathrm{P} 23$ & Normal distribution & $\begin{array}{l}\text { Two-way ANOVA; Tukey post } \\
\text { hoc analysis }\end{array}$ & $\begin{array}{l}\text { SN P23 ablation: } \\
\text { AnkR intensity }\end{array}$ & & \\
\hline & & & & & Effect of genotype & $p<0.0001$ \\
\hline & & & & & Effect of timing postinjection & $p<0.0001$ \\
\hline & & & & & Genotype $\times$ timing interaction & $p<0.0001$ \\
\hline & & & & & Control 10 dpi vs. DKO $10 \mathrm{dpi}$ & $p<0.0001$ \\
\hline & & & & & Control 20 dpi vs. DKO 20 dpi & $p<0.0001$ \\
\hline & & & & & Control 60 dpi vs. DKO 60 dpi & $p=0.8245$ \\
\hline & & & & & DKO 10 dpi vs. 20 dpi & $p<0.0001$ \\
\hline & & & & & DKO 10 dpi vs. 60 dpi & $p<0.0001$ \\
\hline & & & & & DKO 20 dpi vs. 60 dpi & $p<0.0001$ \\
\hline & & & (Conti & & & \\
\hline
\end{tabular}


Table 1. Continued

\begin{tabular}{|c|c|c|c|c|}
\hline Item & Figure & Data structure & Type of test & Description \\
\hline as & $5 S, P 93$ & Normal distribution & $\begin{array}{l}\text { Two-way ANOVA; Tukey post } \\
\text { hoc analysis }\end{array}$ & SN P93 ab \\
\hline
\end{tabular}

Two-way ANOVA; Tukey post hoc analysis

P13 ablation: AnkR intensity
Two-way ANOVA; Tukey post hoc analysis
SC P93 ablation: AnkR intensity

SC- AnkR: relative protein level

P13 ablation: NCV

\section{P13 ablation:} Notch Amp

P23 ablation: NCV
Effect of genotype

Effect of timing postinjection

Genotype $\times$ timing interaction

Control 10 dpi vs. DKO $10 \mathrm{dp}$

Control 20 dpi vs. DKO 20 dpi

Control 120 dpi vs. DKO 120 dpi

DKO 10 dpi vs. 20 dpi

DKO 10 dpi vs. $120 \mathrm{dpi}$

DKO 20 dpi vs. 120 dpi

Effect of genotype

Effect of timing postinjection

Genotype $\times$ timing interaction

Control 10 dpi vs. DKO 10 dpi

Control 20 dpi vs. DKO $20 \mathrm{dpi}$

Control 30 dpi vs. DKO $30 \mathrm{dpi}$

DKO 10 dpi vs. 20 dpi

DKO 10 dpi vs. 30 dpi

DKO 20 dpi vs. 30 dpi

Effect of genotype

Effect of timing postinjection

Genotype $\times$ timing interaction

Control 10 dpi vs. DKO $10 \mathrm{dpi}$

Control 20 dpi vs. DKO $20 \mathrm{dpi}$

Control 60 dpi vs. DKO $60 \mathrm{dpi}$

DKO 10 dpi vs. 20 dpi

DKO 10 dpi vs. $60 \mathrm{dpi}$

DKO 20 dpi vs. $60 \mathrm{dpi}$

Effect of genotype

Effect of timing postinjection

Genotype $\times$ timing interaction

Control 10 dpi vs. DKO $10 \mathrm{dp}$

Control 20 dpi vs. DKO 20 dpi

Control 120 dpi vs. DKO 120 dpi

DKO 10 dpi vs. 20 dpi

DKO 10 dpi vs. $120 \mathrm{dp}$

DKO 20 dpi vs. 120 dpi

Control vs. P13 ablation DKO

Control vs. P23 ablation DKO

Control vs. P93 ablation

Effect of genotype

Effect of timing postinjection

Genotype $\times$ timing interaction

Control $10 \mathrm{dpi}$ vs. DKO $10 \mathrm{dpi}$

Control 20 dpi vs. DKO 20 dpi

Control 30 dpi vs. DKO $30 \mathrm{dp}$

DKO 10 dpi vs. 20 dpi

DKO 10 dpi vs. 30 dpi

DKO 20 dpi vs. $30 \mathrm{dpi}$

Effect of genotype

Effect of timing postinjection

Genotype $\times$ timing interaction

Control 10 dpi vs. DKO $10 \mathrm{dpi}$

Control 20 dpi vs. DKO 20 dp

Control 30 dpi vs. DKO $30 \mathrm{dpi}$

DKO 10 dpi vs. $20 \mathrm{dpi}$

DKO 10 dpi vs. $30 \mathrm{dpi}$

DKO 20 dpi vs. 30 dpi

Effect of genotype

Effect of timing postinjection

Genotype $\times$ timing interaction

Control $10 \mathrm{dpi}$ vs. DKO $10 \mathrm{dp}$

Control 20 dpi vs. DKO 20 dpi
Power

$$
\begin{aligned}
& p<0.0001 \\
& p<0.0001 \\
& p<0.0001 \\
& p=0.0008 \\
& p<0.0001 \\
& p=0.1776 \\
& p<0.0001 \\
& p<0.0001 \\
& p<0.0001
\end{aligned}
$$

$p<0.0001$

$p<0.0002$

$p<0.0003$

$p=0.3295$

$p<0.0001$

$p=0.9979$

$p<0.0001$

$p=0.4570$

$p<0.0001$

$p<0.0001$

$p<0.0001$

$p<0.0001$

$p=0.8577$

$p<0.0001$

$p>0.9999$

$p<0.0001$

$p=0.8179$

$p<0.0001$

$p<0.0001$

$p<0.0001$

$p<0.0001$

$p=0.8502$

$p<0.0001$

$p=0.4611$

$p<0.0001$

$p=0.9796$

$p<0.0001$

$p=0.9677$

$p=0.4293$

$p=0.2763$

$p=0.0927$

$p<0.0001$

$p<0.0001$

$p=0.0005$

$p<0.0001$

$p<0.0001$

$p=0.7586$

$p=0.2018$

$p=0.9264$

$p=0.0006$

$p<0.0001$

$p=0.0016$

$p=0.9992$

$p=0.3675$

$p<0.0001$

$p=0.7221$

$p=0.9993$

$p=0.4799$

$p<0.0001$

$p=0.0428$

$p=0.0171$

$p>0.9999$

0.0021 
Table 1. Continued

\begin{tabular}{|c|c|c|c|c|c|c|}
\hline Item & Figure & Data structure & Type of test & Description & Comparison & Power \\
\hline & & & & & Control 60 dpi vs. DKO 60 dpi & 0.0004 \\
\hline & & & & & DKO 10 dpi vs. 20 dpi & $p>0.9999$ \\
\hline & & & & & DKO 10 dpi vs. 60 dpi & $p=0.9991$ \\
\hline & & & & & DKO 20 dpi vs. 60 dpi & $p=0.9998$ \\
\hline \multirow[t]{10}{*}{ ba } & $6 F$ & Normal distribution & $\begin{array}{l}\text { Two-way ANOVA; Tukey post } \\
\text { hoc analysis }\end{array}$ & $\begin{array}{l}\text { P23 ablation: } \\
\text { Notch Amp }\end{array}$ & & \\
\hline & & & & & Effect of genotype & $p=0.0007$ \\
\hline & & & & & Effect of timing postinjection & $p=0.5107$ \\
\hline & & & & & Genotype $\times$ timing interaction & $p=0.4310$ \\
\hline & & & & & Control 10 dpi vs. DKO $10 \mathrm{dpi}$ & $p=0.9582$ \\
\hline & & & & & Control 20 dpi vs. DKO 20 dpi & $p=0.0492$ \\
\hline & & & & & Control 60 dpi vs. DKO $60 \mathrm{dpi}$ & $p=0.034$ \\
\hline & & & & & DKO 10 dpi vs. 20 dpi & $p=0.6092$ \\
\hline & & & & & DKO 10 dpi vs. 60 dpi & $p=0.8662$ \\
\hline & & & & & DKO 20 dpi vs. 60 dpi & $p=0.9906$ \\
\hline \multirow[t]{10}{*}{$\mathrm{bb}$} & $6 H$ & Normal distribution & $\begin{array}{l}\text { Two-way ANOVA; Tukey post } \\
\text { hoc analysis }\end{array}$ & P93 ablation: NCV & & \\
\hline & & & & & Effect of genotype & $p<0.0001$ \\
\hline & & & & & Effect of timing postinjection & $p=0.9269$ \\
\hline & & & & & Genotype $\times$ timing interaction & $p=0.0770$ \\
\hline & & & & & Control 20 dpi vs. DKO 20 dpi & $p=0.8318$ \\
\hline & & & & & Control 60 dpi vs. DKO 60 dpi & $p=0.0002$ \\
\hline & & & & & Control 120 dpi vs. DKO 120 dpi & $p=0.0644$ \\
\hline & & & & & DKO 20 dpi vs. 60 dpi & $p=0.9163$ \\
\hline & & & & & DKO 20 dpi vs. 120 dpi & $p=0.4341$ \\
\hline & & & & & DKO 60 dpi vs. 120 dpi & $p=0.9652$ \\
\hline \multirow[t]{10}{*}{ bc } & $6 /$ & Normal distribution & $\begin{array}{l}\text { Two-way ANOVA; Tukey post } \\
\text { hoc analysis }\end{array}$ & $\begin{array}{l}\text { P93 ablation: } \\
\text { Notch Amp }\end{array}$ & & \\
\hline & & & & & Effect of genotype & $p=0.0213$ \\
\hline & & & & & Effect of timing postinjection & $p=0.0088$ \\
\hline & & & & & Genotype $\times$ timing interaction & $p=0.0174$ \\
\hline & & & & & Control 20 dpi vs. DKO 20 dpi & $p>0.9999$ \\
\hline & & & & & Control 60 dpi vs. DKO 60 dpi & $p=0.0713$ \\
\hline & & & & & Control 120 dpi vs. DKO 120 dpi & $p=0.0041$ \\
\hline & & & & & DKO 20 dpi vs. 60 dpi & $p>0.9999$ \\
\hline & & & & & DKO 20 dpi vs. 120 dpi & $p=0.3463$ \\
\hline & & & & & DKO 60 dpi vs. 120 dpi & $p=0.4148$ \\
\hline
\end{tabular}

Note: GraphPad Prism, which was used to perform all statistical analyses, does not report exact $p$-values higher than 0.9999 or lower than 0.0001 .

All statistical tests are summarized with exact $p$-values.

\section{References}

Albert M (1993) Neuropsychological and neurophysiological changes in healthy adult humans across the age range. Neurobiol Aging 14:623-625. Medline

Amor V, Feinberg K, Eshed-Eisenbach Y, Vainshtein A, Frechter S, Grumet M, Rosenbluth J, Peles E (2014) Long-term maintenance of $\mathrm{Na}+$ channels at nodes of Ranvier depends on glial contact mediated by gliomedin and NrCAM. J Neurosci 34:5089-5098. CrossRef Medline

Bhat MA, Rios JC, Lu Y, Garcia-Fresco GP, Ching W, St Martin M, Li J, Einheber S, Chesler M, Rosenbluth J, Salzer JL, Bellen HJ (2001) Axon-glia interactions and the domain organization of myelinated axons requires neurexin IV/Caspr/Paranodin. Neuron 30:369-383. Medline

Bilbao JM, Schmidt RE (2014) Biopsy Diagnosis of Peripheral Neuropathy. New York: Springer International.

Boiko T, Rasband MN, Levinson SR, Caldwell JH, Mandel G, Trimmer JS, Matthews G (2001) Compact myelin dictates the differential targeting of two sodium channel isoforms in the same axon. Neuron 30:91-104. Medline

Boyle ME, Berglund EO, Murai KK, Weber L, Peles E, Ranscht B (2001) Contactin orchestrates assembly of the septate-like junctions at the paranode in myelinated peripheral nerve. Neuron 30:385-397. Medline

Buttermore ED, Thaxton CL, Bhat MA (2013) Organization and maintenance of molecular domains in myelinated axons. J Neurosci Res 91:603-622. CrossRef Medline

Caroni P (1997) Overexpression of growth-associated proteins in the neurons of adult transgenic mice. J Neurosci Methods 71:3-9. Medline
Chang KJ, Zollinger DR, Susuki K, Sherman DL, Makara MA, Brophy PJ, Cooper EC, Bennett V, Mohler PJ, Rasband MN (2014) Glial ankyrins facilitate paranodal axoglial junction assembly. Nat Neurosci 17:1673-1681. CrossRef Medline

Coman I, Aigrot MS, Seilhean D, Reynolds R, Girault JA, Zalc B, Lubetzki C (2006) Nodal, paranodal and juxtaparanodal axonal proteins during demyelination and remyelination in multiple sclerosis. Brain 129:3186-3195. CrossRef Medline

Craner MJ, Newcombe J, Black JA, Hartle C, Cuzner ML, Waxman SG (2004) Molecular changes in neurons in multiple sclerosis: altered axonal expression of Nav1.2 and Nav1.6 sodium channels and $\mathrm{Na}+/ \mathrm{Ca} 2+$ exchanger. Proc Natl Acad Sci U S A 101:81688173. CrossRef Medline

Davis JQ, Lambert S, Bennett V (1996) Molecular composition of the node of Ranvier: identification of ankyrin-binding cell adhesion molecules neurofascin (mucin+/third FNIII domain-) and NrCAM at nodal axon segments. J Cell Biol 135:1355-1367. Medline

Desmazières A, Sol-Foulon N, Lubetzki C (2012) Changes at the nodal and perinodal axonal domains: a basis for multiple sclerosis pathology? Mult Scler 18:133-137. CrossRef Medline

Desmazieres A, Zonta B, Zhang A, Wu LM, Sherman DL, Brophy PJ (2014) Differential stability of PNS and CNS nodal complexes when neuronal neurofascin is lost. J Neurosci 34:5083-5088. CrossRef Medline

Devaux JJ, Odaka M, Yuki N (2012) Nodal proteins are target antigens in Guillain-Barré syndrome. J Peripher Nerv Syst 17:62-71. CrossRef Medline

Dzhashiashvili Y, Zhang Y, Galinska J, Lam I, Grumet M, Salzer JL (2007) Nodes of Ranvier and axon initial segments are ankyrin G-dependent domains that assemble by distinct mechanisms. J Cell Biol 177:857-870. CrossRef Medline 
Green JA, Yang J, Grati M, Kachar B, Bhat MA (2013) Whirlin, a cytoskeletal scaffolding protein, stabilizes the paranodal region and axonal cytoskeleton in myelinated axons. BMC Neurosci 14: 96. CrossRef Medline

Haines JD, Inglese M, Casaccia P (2011) Axonal damage in multiple sclerosis. Mt Sinai J Med 78:231-243. CrossRef Medline

Halter JA, Clark JW, Jr. (1993) The influence of nodal constriction on conduction velocity in myelinated nerve fibers. Neuroreport 4:8992. Medline

Heimer-McGinn V, Young P (2011) Efficient inducible Pan-neuronal cre-mediated recombination in SLICK-H transgenic mice. Genesis 49:942-949. CrossRef Medline

Hinman JD, Peters A, Cabral H, Rosene DL, Hollander W, Rasband MN, Abraham CR (2006) Age-related molecular reorganization at the node of Ranvier. J Comp Neur 495:351-362. CrossRef Medline

Ho TS, Zollinger DR, Chang KJ, Xu M, Cooper EC, Stankewich MC, Bennett V, Rasband MN (2014) A hierarchy of ankyrin-spectrin complexes clusters sodium channels at nodes of Ranvier. Nat Neurosci 17:1664-1672. CrossRef Medline

Jenkins PM, Kim N, Jones SL, Tseng WC, Svitkina TM, Yin HH, Bennett V (2015) Giant ankyrin-G: a critical innovation in vertebrate evolution of fast and integrated neuronal signaling. Proc Natl Acad Sci U S A 112:957-964. CrossRef Medline

Jenkins SM, Bennett V (2002) Developing nodes of Ranvier are defined by ankyrin-G clustering and are independent of paranodal axoglial adhesion. Proc Natl Acad Sci U S A 99:2303-2308. CrossRef Medline

Johnson C, Holmes WR, Brown A, Jung P (2015) Minimizing the caliber of myelinated axons by means of nodal constrictions. $J$ Neurophysiol 114:1874-1884. CrossRef Medline

Kaplan MR, Cho MH, Ullian EM, Isom LL, Levinson SR, Barres BA (2001) Differential control of clustering of the sodium channels $\mathrm{Na}(\mathrm{v}) 1.2$ and $\mathrm{Na}(\mathrm{v}) 1.6$ at developing CNS nodes of Ranvier. Neuron 30:105-119. Medline

Knox CA, Kokmen E, Dyck PJ (1989) Morphometric alteration of rat myelinated fibers with aging. J Neuropathol Exp Neurol 48:119139. Medline

Komada M, Soriano P (2002) [Beta]IV-spectrin regulates sodium channel clustering through ankyrin-G at axon initial segments and nodes of Ranvier. J Cell Biol 156:337-348. CrossRef

Kordeli E, Lambert S, Bennett V (1995) AnkyrinG. A new ankyrin gene with neural-specific isoforms localized at the axonal initial segment and node of Ranvier. J Biol Chem 270:2352-2359. Medline

Lambert S, Davis JQ, Bennett V (1997) Morphogenesis of the node of Ranvier: co-clusters of ankyrin and ankyrin-binding integral proteins define early developmental intermediates. J Neurosci 17: 7025-7036. Medline
Lonigro A, Devaux JJ (2009) Disruption of neurofascin and gliomedin at nodes of Ranvier precedes demyelination in experimental allergic neuritis. Brain 132:260-273. CrossRef Medline

Luessi F, Siffrin V, Zipp F (2012) Neurodegeneration in multiple sclerosis: novel treatment strategies. Expert Rev Neurother 12: 1061-1076. quiz 1077. CrossRef

Nelson AD, Jenkins PM (2017) Axonal membranes and their domains: assembly and function of the axon initial segment and node of Ranvier. Front Cell Neurosci 11:136. CrossRef Medline

Paez-Gonzalez P, Abdi K, Luciano D, Liu Y, Soriano-Navarro M, Rawlins E, Bennett V, Garcia-Verdugo JM, Kuo CT (2011) Ank3dependent SVZ niche assembly is required for the continued production of new neurons. Neuron 71:61-75. CrossRef Medline

Peters A (2002) The effects of normal aging on myelin and nerve fibers: a review. J Neurocytol 31:581-593. Medline

Pillai AM, Thaxton C, Pribisko AL, Cheng JG, Dupree JL, Bhat MA (2009) Spatiotemporal ablation of myelinating glia-specific neurofascin (Nfasc NF155) in mice reveals gradual loss of paranodal axoglial junctions and concomitant disorganization of axonal domains. J Neurosci Res 87:1773-1793. CrossRef Medline

Saifetiarova J, Taylor AM, Bhat MA (2017) Early and late loss of the cytoskeletal scaffolding protein, ankyrin $\mathrm{G}$ reveals its role in maturation and maintenance of nodes of Ranvier in myelinated axons. J Neurosci 37:2524-2538.

Sward C, Berthold CH, Nilsson-Remahl I, Rydmark M (1995) Axonal constriction at Ranvier's node increases during development. Neurosci Lett 190:159-162. CrossRef

Taylor AM, Saifetiarova J, Bhat MA (2017) Postnatal loss of neuronal and glial neurofascins differentially affects node of Ranvier maintenance and myelinated axon function. Front Cell Neurosci 11:11. CrossRef Medline

Thaxton C, Pillai AM, Pribisko AL, Dupree JL, Bhat MA (2011) Nodes of Ranvier act as barriers to restrict invasion of flanking paranodal domains in myelinated axons. Neuron 69:244-257. CrossRef Medline

Young P, Qiu L, Wang D, Zhao S, Gross J, Feng G (2008) Singleneuron labeling with inducible Cre-mediated knockout in transgenic mice. Nat Neurosci 11:721-728. CrossRef Medline

Zhang Y, Bekku Y, Dzhashiashvili Y, Armenti S, Meng X, Sasaki Y, Milbrandt J, Salzer JL (2012) Assembly and maintenance of nodes of Ranvier rely on distinct sources of proteins and targeting mechanisms. Neuron 73:92-107. CrossRef Medline

Zonta B, Desmazieres A, Rinaldi A, Tait S, Sherman DL, Nolan MF, Brophy PJ (2011) A critical role for Neurofascin in regulating action potential initiation through maintenance of the axon initial segment. Neuron 69:945-956. CrossRef Medline 